ß-Lapachona: Sua Importância em Química Medicinal e Modificações Estruturais

\author{
Ferreira, S. B.; Gonzaga, D. T. G.; Santos, W. C.; Araújo, K. G. L.; Ferreira, V. F.* \\ Rev. Virtual Quim., 2010, 2 (2), 140-160. Data de publicação na Web: 01 de outubro de 2010 \\ http://www.uff.br/rvq
}

\title{
$\beta$-Lapachone: Medicinal Chemistry Significance and Structural Modifications
}

Abstract: This mini-review describes the work of Brazilian researchers who started the investigations about lapachol and $\beta$-lapachone, a natural product of inspiring a series of papers on new substances with anticancer activity, trypanocidal, antinflammatory, tuberculostatics and antimalarial. Among these studies, we report some of the most important structural changes made in the carbonyl functions of these naphthoquinones, presenting the main results achieved in medicinal chemistry.

Keywords: $\beta$-lapachone; naphthoquinone; Oswaldo Gonçalves de Lima; Antonio Ventura Pinto

\section{Resumo}

Esta mini-revisão descreve o trabalho de pesquisadores brasileiros que iniciaram a pesquisa com o lapachol e a $\beta$-lapachona, produtos naturais inspiradores de uma série de trabalhos científicos sobre novas substâncias com atividade anti-câncer, tripanocida, anti-inflamatória, tuberculostática e anti-malarial . Entre estas pesquisas, são apresentadas algumas das mais importantes modificações estruturais realizadas nas funções carbonílicas destas naftoquinonas, apresentando os principais resultados obtidos no âmbito da química medicinal.

palavras-chave: $\beta$-lapachona; naftoquinona; Oswaldo Gonçalves de Lima; Antonio Ventura Pinto

\footnotetext{
* Universidade Federal Fluminense, Instituto de Química, Campus do Valonguinho, 24020-150 Niterói, RJ, Brasil. M cegvito@vm.uff.br DOI: $\underline{10.5935 / 1984-6835.20100013}$
} 


\title{
ß-lapachona: Sua Importância em Química Medicinal e Modificações Estruturais
}

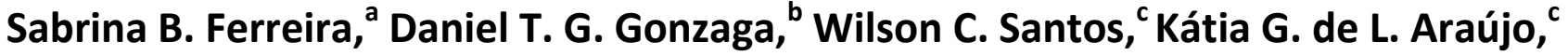 \\ Vitor F. Ferreira, ${ }^{b}$ * \\ aUniversidade Federal do Rio de Janeiro, Instituto de Química, Departamento de Química Orgânica, 27930-560, \\ Macaé - RJ, Brasil. \\ 'Universidade Federal Fluminense, Instituto de Química, Campus do Valonguinho, 24020-150, Niterói, RJ, Brasil. \\ 'Universidade Federal Fluminense, Faculdade de Farmácia, CEP24241-000, Niterói, RJ, Brasil. \\ *cegvito@vm.uff.br
}

Recebido em 06 de agosto de 2009. Aceito para publicação em 31 de outubro de 2009

\section{Introdução}

\section{Quinonas e Naftoquinonas}

2.1. $\beta$-lapachona: Importante naftoquinona cromânica de origem natural

\section{Modificações nas carbonilas da $\beta$-lapachona}

3.1. Reações de mono adição no sistema naftoquinônico

3.2. Reações de formação de heterociclos no sistema naftoquinônico

\section{Comentários finais}

\section{Introdução}

As quinonas representam uma ampla e variada família de metabólitos secundários de ocorrência natural. $O$ interesse por estas substâncias foi intensificado nos últimos anos devido à sua importância farmacológica.

No Brasil, muitos grupos de pesquisa fizeram do estudo destas substâncias uma de suas linhas de pesquisa. O lapachol (1) e a $\beta$-lapachona (2) (Figura 1) podem ser consideradas as naftoquinonas que mais influenciaram os grupos brasileiros de pesquisa em química e farmacologia de quinonas.<smiles>CC(C)=CCC1=C(O)C(=O)c2ccccc2C1=O</smiles>

1

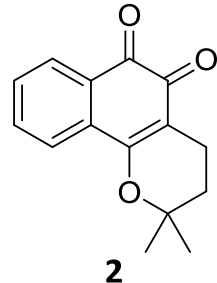

Figura 1. Lapachol (1) e $\beta$-lapachona (2)
A $\beta$-lapachona (2) é uma substância natural facilmente obtida a partir do lapachol (1). Esta naftoquinona é o grande destaque desta classe de substâncias porque se encontra em testes clínicos de fase II para o tratamento do câncer de pâncreas. ${ }^{1}$

Estas naftoquinonas foram investigadas como antimicrobianas, tripanocidas e anticancerígenas. Modificações em suas estruturas foram realizadas, inicialmente, por dois grandes pesquisadores brasileiros: Oswaldo Gonçalves de Lima (UFPe, Quadro 1) e Antonio Ventura Pinto (UFRJ-NPPN, Quadro 2). Ambos são químicos industriais formados pela UFRJ. As linhas de investigação destes dois pesquisadores tiveram diferentes enfoques, o primeiro mais voltado para as investigações farmacológicas e o segundo para os aspectos sintéticos, dirigidos para a síntese de novas substâncias e de suas atividades biológicas. Os dois dedicaram muito tempo de suas vidas aos estudos com as naftoquinonas $\mathbf{1}$ e $\mathbf{2}$ e formaram diversos pesquisadores nesta área de investigação. 
Quadro 1. Biografia resumida do Prof. Oswaldo G. de Lima

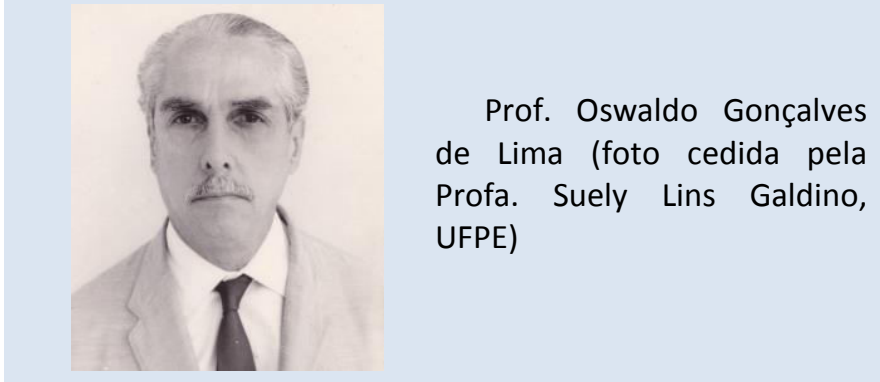

O químico industrial pernambucano Oswaldo Gonçalves de Lima $\left(7 / 11 / 1908\right.$ - 21/09/1989) ${ }^{2}$ foi um cientista de grande expressão no Brasil. Obteve o título de químico, em 1928, pela Escola Nacional de Química da Universidade do Brasil. Em 1934 se tornou Professor Catedrático de Química Analítica Quantitativa e, posteriormente, transferiu-se para a Cátedra de Microbiologia e Técnica das Fermentações na Universidade do Recife. Com a fundação da Universidade Federal de Pernambuco (UFPE) em 1947, organizou e tornou-se Diretor da Escola Superior de Química desta Universidade. Em 8 de março de 1952 fundou o Instituto de Antibióticos de Pernambuco, permanecendo como seu Diretor por mais de 30 anos. $^{3}$ Este Instituto se tornou um dos principais centros de pesquisa do Brasil na área de antibióticos, e foi reconhecido internacionalmente pela qualidade do trabalho de seus pesquisadores.

Numa época em que a produção de antibióticos em laboratório ainda era uma fronteira para a investigação científica, os trabalhos desenvolvidos pelo Professor Oswaldo Gonçalves de Lima foram de grande significado para o desenvolvimento da farmacologia moderna. Foi o primeiro cientista do Nordeste a ser eleito Membro Titular da Academia Brasileira de Ciências (1953). Em 1956 isolou o lapachol (1) do cerne do Ipê-Roxo ("árvore buquê"). Esta substância era conhecida desde 1858 e sua estrutura foi elucidada em 1882. ${ }^{4,5}$ Desde então, tem sido encontrada como constituinte de várias plantas das famílias Bignoniaceae, Verbenaceae e Proteaceae. Oswaldo Gonçalves de Lima e colaboradores ${ }^{6}$ foram os primeiros a descreverem a atividade antimicrobiana do lapachol frente a cepas de Bacillus subtilis, Staphylococcus aureus, Micrococcus flavus, B. anthracis, B. cereus e Escherichia coli. Em seguida, estes pesquisadores demonstraram que o extrato do ipê-roxo tinha atividade anticancerígena em tumores experimentais, ${ }^{7}$ tornando o lapachol e seus derivados alvos de interesse de diversos grupos de pesquisa. ${ }^{8}$ Posteriormente, Rao e colaboradores demonstraram, além da sua ação analgésica, a atividade sobre o sarcoma de Yoshida, com promoção da regressão definitiva de neoplasias em aproximadamente $30 \%$ dos portadores destas patologias. ${ }^{9}$
Este trabalho não trata somente de uma revisão sobre as pesquisas destes eminentes professores, mas tem o intuito de ressaltar suas valiosas contribuições para o conhecimento das propriedades químicas e farmacológicas das quinonas.

Atualmente a empresa ArQule ${ }^{12}$ está conduzindo os testes clínicos de fase $\|{ }^{1}$ com a $\beta$-lapachona ou ARQ-501 (2), muito disso é devido aos trabalhos do Prof. Ventura no Rio de Janeiro e, anteriormente, aos de Oswaldo Gonçalves de Lima, em Pernambuco.

Quadro 2. Biografia resumida do Prof. Antonio V. Pinto

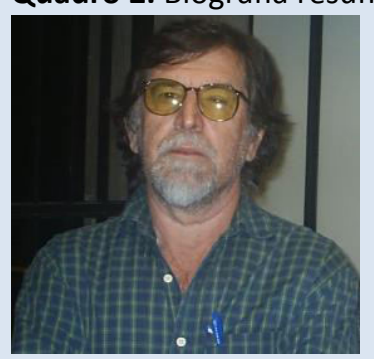

Prof. Antônio Ventura Pinto (Cortesia do pesquisador)

O químico industrial carioca Antonio Ventura Pinto (20/05/1945 - 18/03/2010) obteve em 1968 sua graduação no Instituto de Química da Universidade Federal do Rio de Janeiro. Neste mesmo Instituto doutorou-se, em 1976, sob a orientação do Prof. Warner B. Kover. Em 1974 ingressou como pesquisador no Centro de Pesquisas de Produtos Naturais, atualmente Núcleo de Pesquisas de Produtos Naturais (NPPN), onde foi trabalhar com o Prof. Benjamin Gilbert. Por sugestão do Prof. Gilbert, iniciou suas pesquisas com o lapachol e com a $\alpha$ - e a $\beta$-lapachona. Em 1977 publicou seu primeiro trabalho na revista da Sociedade de Medicina Tropical da Inglaterra, quando demonstrou que estas naftoquinonas e alguns de seus derivados bloqueavam a penetração de cercárias do Schistosoma mansoni (agente etiológico da esquistossomose) na pele de ratos.

Seus trabalhos com a $\beta$-lapachona (2) e derivados despertaram a atenção do Prof. Arthur B. Pardee (Department of Biological Chemistry and Molecular Pharmacology, Harvard Medical School), para quem enviou grande quantidade desta substância para testes in vivo e in vitro. Estes testes demonstraram que a combinação da $\beta$ lapachona (2) com o taxol impõe pontos de checagem artificiais na replicação do DNA em células tumorais. ${ }^{10}$ Logo a seguir, Pardee e colaboradores demonstraram que a apoptose e a necrose são induzidas pela $\beta$-lapachona em carcinomas humanos. ${ }^{11}$ Esta linha de investigação continua até os dias atuais com o grupo do Prof. Pardee, e em outras instituições americanas. O professor Ventura nos deixou recentemente, mas graças aos seus trabalhos, vários pesquisadores brasileiros continuarão se dedicando, aos estudos das naftoquinonas como protótipo para substâncias bioativas. 
O Professor Antônio Ventura Pinto contribuiu intensivamente com seus trabalhos sobre modificações estruturais de $\beta$-lapachona para 0 conhecimento da reatividade química desta naftoquinona e de suas propriedades farmacológicas. Vários destes trabalhos são citados ao longo deste artigo.

Após as importantes contribuições desses dois pesquisadores brasileiros, diversos grupos de pesquisas no Brasil e em outros países têm trabalhado intensamente com estas quinonas, principalmente na química do lapachol (1), $\beta$-lapachona (2) e seus derivados, na busca de compostos bioativos.

\section{Quinonas e Naftoquinonas}

As quinonas naturais e sintéticas são substâncias reconhecidamente possuidoras de potentes $\mathrm{e}$ variados tipos de atividades biológicas como antitumorais, ${ }^{13-15}$ moluscicidas, ${ }^{16-18}$ leishmanicidas, ${ }^{19}$ anti-inflamatórias, ${ }^{20}$ antifúngicas, ${ }^{21}$ tripanocidas, ${ }^{22,23}$ antiprotozoárias $^{24}$ e inibidoras da enzima transcriptase reversa do vírus HIV- $1 .{ }^{25}$ A grande variedade estrutural de quinonas de origem natural, como por exemplo, a $\beta$-lapachona (2), $\alpha$-lapachona (3), estreptonigrina (4) e urdamicinona (5), obtidas de extratos vegetais (Figura 2), têm despertado grande interesse da comunidade científica. Este fato pode ser comprovado pelo grande número de trabalhos encontrados na literatura, explorando a atuação destas substâncias em múltiplas funções biológicas. ${ }^{26-}$ 29<smiles>COC1=C(N)C(=O)c2nc(-c3nc(C(=O)O)c(C)c(-c4ccc(OC)c(OC)c4O)c3N)ccc2C(=O)C1=O</smiles><smiles>CC1(C)OC(c2ccc3c(c2O)C(=O)c2ccc4c(c2C3=O)C(=O)C[C@](C)(O)C4)[C@H](O)C1(C)O</smiles>

Figura 2. Exemplos de quinonas de origem natural

A quimioterapia para a doença de Chagas e para o câncer tem alguns pontos em comum no que diz respeito às quinonas. Por exemplo, a $\beta$-lapachona é um potente tripanocida e bastante citotóxica para células tumorais. Parte do mecanismo de ação das quinonas envolve a geração de espécies reativas de oxigênio (ROS) induzidas pela biorredução do núcleo quinonoídico por enzimas específicas e oxigênio, ${ }^{30,31}$ as quais são tóxicas para o Trypanossoma cruzi e induzem apoptoses e/ou interagem com topoisomerases das células tumorais.

A doença de Chagas, causada pelo parasita T. cruzi, é endêmica na América Latina. É um grave problema de saúde pública em vários países, com 16 a 18 milhões de pessoas infectadas com o parasita, e mais de 100 milhões em risco de infecção, quer através do contato com um inseto vetor ou através de transfusão sanguínea. ${ }^{32} \mathrm{O}$ ciclo de vida do $T$. cruzi envolve vários estágios do parasita no hospedeiro e transmissor. 0 único agente terapêutico disponível no Brasil para o tratamento da doença de Chagas é o benzonidazol (6, Rochagan $^{\circledR}$, Figura 3 ), fármaco da década de 70 . Este nitro derivado além de nem sempre ser eficaz, provoca efeitos colaterais graves como hipersensibilidade, dermatite com erupções cutâneas, edema generalizado, febre, linfoadenopatia, e dores articulares e musculares. ${ }^{33} \mathrm{Na}$ ausência de tratamento específico, a fase aguda da doença de Chagas persiste durante cerca de dois meses, com uma mortalidade global de 2 a $8 \%$, principalmente entre as crianças. $\mathrm{Na}$ fase crônica, a maioria dos pacientes permanece assintomática (fase indeterminada), com cerca de $20 \%$ dos casos desenvolvendo doença cardíaca irreversível, doença digestiva, ou perturbações neurológicas. $O$ tratamento clínico de pacientes crônicos permanece controverso. ${ }^{19}$

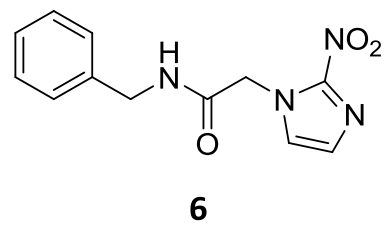

Figura 3. Fármaco benzonidazol (Rochagan ${ }^{\circledR}$ ) utilizado no tratamento da doença de Chagas

O câncer é a segunda causa de morte mais comum no mundo. Esta enfermidade compreende um conjunto de mais de 100 doenças que têm em comum o crescimento desordenado de células que invadem os tecidos e órgãos, podendo espalhar-se para outras regiões do corpo, num processo conhecido como metástase. $\mathrm{O}$ tratamento envolve diversas ações que incluem a remoção cirúrgica do tumor, quimioterapia, radioterapia ou a combinação destes tratamentos. Lesões carcinogênicas têm sido associadas à deficiência de reparação do DNA. É fundamental para uma célula a reparação com precisão do seu DNA. Em

Rev. Virtual Quim. |Vol 2| |No. 2| |140-160| 
determinadas circunstâncias, se o dano ao DNA não puder ser reparado completamente com alta precisão, é mais vantajoso para o organismo descartar essas células severamente danificadas. As células sobreviventes transformam-se em células neoplásicas. Inibidores da reparação do DNA têm o potencial para agir como fármacos anticâncer. A geração de espécies ânions radicais superóxidos $\left(\mathrm{O}_{2}{ }^{-}\right)$, radicais hidroxila ( $(\mathrm{OH})$, peróxido de hidrogênio $\left(\mathrm{H}_{2} \mathrm{O}_{2}\right)$ e oxigênio singlete $\left({ }^{1} \mathrm{O}_{2}\right)^{34}$ são responsáveis pela condição descrita como estresse oxidativo no interior da célula, causando danos irreversíveis em alguns de seus componentes, podendo levar à morte celular programada (apoptose). ${ }^{35-37}$ O Esquema 1 mostra resumidamente o ciclo redox das quinonas onde 0 substrato quinonoídico $(\mathrm{Q})$ sofre biorredução por um ou dois elétrons, catalisada pelas enzimas NADPH, dentre outras, formando a espécie ânion radical semi- quinona $\left(\mathrm{Q}^{-*}\right)$ in situ. ${ }^{38,39} \mathrm{Na}$ presença de oxigênio molecular $\left(\mathrm{O}_{2}\right)$, esse ânion radical $\left(\mathrm{Q}^{*}\right)$ transfere um elétron e gera o radical superóxido $\left(\mathrm{O}_{2}^{-}\right)$. O radical superóxido $\left(\mathrm{O}_{2}{ }^{-}\right)$sofre a ação da enzima superóxido desmutase gerando peróxido de hidrogênio, e paralelamente uma reação de Fenton catalisada por $\mathrm{Fe}^{+2}$ produz o radical hidroxila. ${ }^{40} \mathrm{~A}$ transferência de elétron e a cinética do processo de geração destas espécies são dependentes do potencial de redução da quinona envolvida no processo, ou seja, está na sua capacidade intrínseca de aceitar elétrons, e esta, por sua vez, está relacionada à presença de substituintes na porção quinonoídica que modula as propriedades redox. Devido a este processo, as quinonas são citotóxicas para as células cancerígenas e normais, e também atuam nas enzimas topoisomerases, que são críticas para a replicação do DNA. ${ }^{41}$

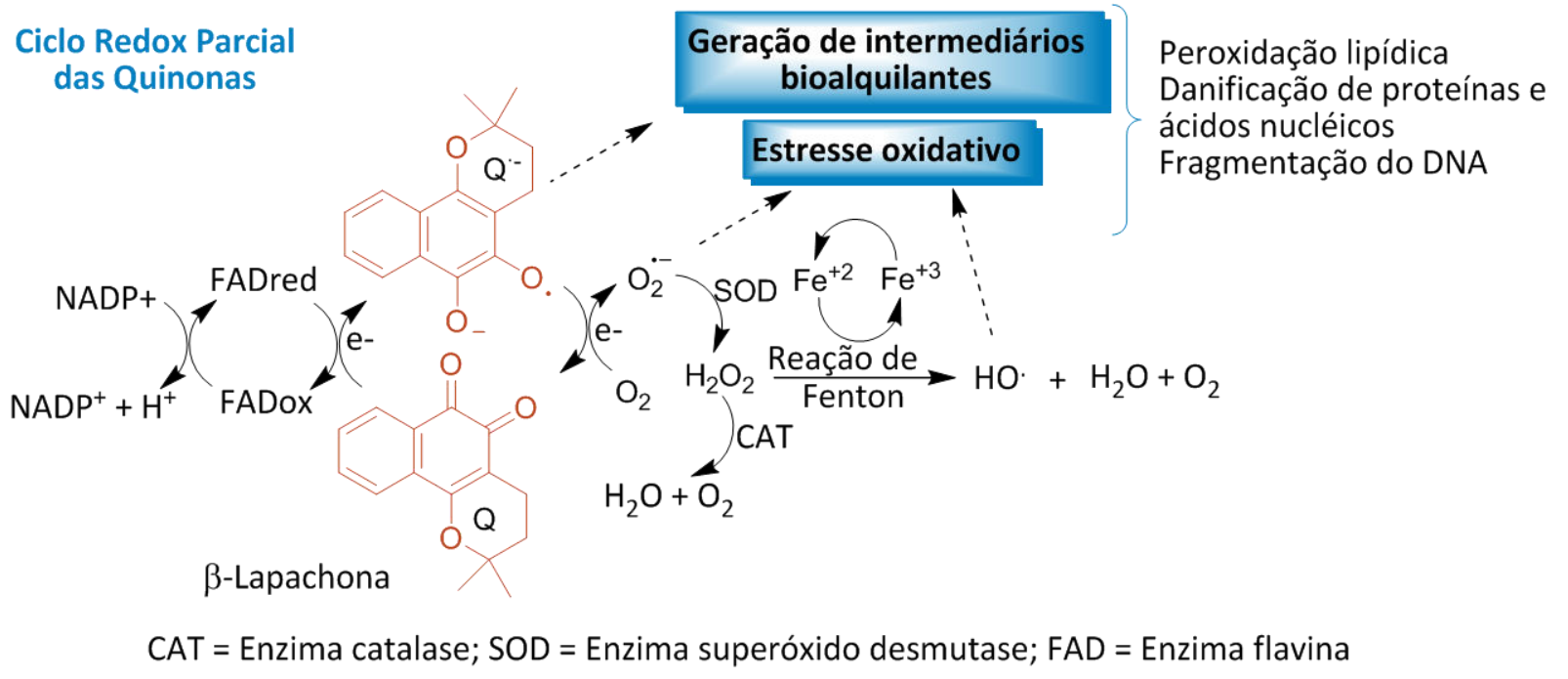

Esquema 1. Resumo esquemático do ciclo redox das quinonas

As naftoquinonas são quinonas relacionadas com o sistema naftalênico. Quando duas carbonilas estão nas posições 1,2 do anel naftaleno são chamadas de $o$-naftoquinonas (7) e quando nas posições 1,4 de $p$ naftoquinonas (8). Estão disseminadas no reino vegetal e, devido às suas propriedades redox, podem interferir em diferentes processos oxidativos biológicos (Figura 4).<smiles>O=C1C=Cc2ccccc2C1=O</smiles>

7 o-Naftoquinona<smiles>O=C1C=CC(=O)c2ccccc21</smiles>

$8 p$-Naftoquinona
Figura 4. Formas isoméricas orto e para-quinonoídica
As plantas que possuem estas quinonas são amplamente utilizadas na medicina popular no tratamento de diversas enfermidades..$^{42}$ Os primeiros relatos da utilização de extratos de plantas que possuem naftoquinonas datam do Antigo Egito (cerca de 4.000 anos atrás). O extrato das folhas de Lawsonia inermis, rico em lausona (9), era empregado como cosmético para a pintura de cabelos, unhas e pele. Posteriormente, o extrato também passou a ser usado no tratamento de micoses e feridas. Na Grécia, entre os séculos $\mathrm{V}$ e IV a.C, o uso do extrato das raízes de Alkania tinctoria, rico em shiconina (10), era utilizado no tratamento de úlceras, feridas, ferimentos de guerra e picadas de cobra (Figura 5). ${ }^{43}$

As naftoquinonas que mais se destacam na literatura contendo anéis cromenos e cromanos são as $\alpha$ - e $\beta$-xiloidonas (11 e $\mathbf{1 2}$ ) e as $\alpha$ - e $\beta$-lapachonas 
(3 e 2), respectivamente. Estas duas últimas quinonas são importantes e diferem das xiloidonas, por não terem a ligação dupla no anel pirano (Figura 6).<smiles>O=C1C=C(O)C(=O)c2ccccc21</smiles>

9 Lausona<smiles>CC(C)=CC[C@@H](O)C1=CC(=O)c2c(O)ccc(O)c2C1=O</smiles>

10 Shiconina
Figura 5. Naftoquinonas naturais
$11 \alpha$-Xiloidona<smiles>CC1(C)C=CC2=C(O1)C(=O)c1ccccc1C2=O</smiles><smiles>CC1(C)C=CC2=C(O1)c1ccccc1C(=O)C2=O</smiles>

$12 \beta$-Xiloidona
Figura 6. Estruturas das $\alpha$ e $\beta$-xiloidonas

2.1. $\beta$-lapachona: Importante naftoquinona cromânica de origem natural

A $\beta$-lapachona (7,8-benzo-2,2-dimetil-3,4-diidro5,6-oxo-2H-cromeno) (2) é descrita na literatura como um dos mais importantes cromanos derivados do lapachol (3). É uma substância natural encontrada como constituinte minoritário do cerne de árvores da família Bignoniaceae, conhecidas no Brasil como ipês. Esta naftoquinona natural é conhecida desde 1858, e é facilmente extraída da serragem da madeira de espécies de ipês.

A $\beta$-lapachona, apesar de ainda não ser um fármaco, é uma substância muito importante do ponto de vista da pesquisa científica. Suas atividades farmacológicas contra o Trypanossoma cruzi, agente etiológico causador da doença de Chagas, e contra células cancerosas, a distingue de outras naftoquinonas. Devido à sua citotoxicidade, a $\beta$ lapachona não pode ser utilizada no tratamento da doença de Chagas, mas sua estrutura tem servido de inspiração para os químicos medicinais, para a síntese de substâncias mais seletivas contra o $T$. cruzi. A $\beta$ lapachona é eficaz, in vitro, contra diversas linhagens de células malignas humanas: de melaloma, leucemia, câncer colorretal, cancêr de pulmão, de mama e de próstata. Outra atividade surpreendente da $\beta$ lapachona é a sua ação sinergística no tratamento radioterápico de tumores. Por exemplo, ela aumenta em $79 \%$ a eficiência da radiação sobre células de melanoma humano (U1-Mel), resistentes à radiação. Este efeito é devido a indução da apoptose, morte celular programada, causada pela energia ionizante e por substâncias indutoras de apoptose. Tanto a radiação, quanto os inibidores do complexo DNAtopoisomerase, provocam danos ao DNA das células cancerosas. ${ }^{44}$

Os mecanismos de atuação da $\beta$-lapachona ainda não estão bem delineados. Há evidências que ela age inibindo as enzimas topoisomerases I e II, pois a incubação direta desta substância com a topoisomerase I, antes da adição de DNA como substrato, aumenta drasticamente o seu efeito inibitório, sugerindo a interação direta da $\beta$ lapachona com a topoisomerase I.

Há evidências da participação da enzima NAD(P)H: quinona oxirreductase-1 (NQO1) no processo de ativação da $\beta$-lapachona na apoptose. A NQO1 é expressa em maiores concentrações em vários tipos de tumores, incluindo os de mama, pulmão e colorretal, do que em tecidos normais. Foi recentemente demonstrado que a $\beta$-lapachona é um agente terapêutico efetivo e um radiossensibilizador capaz de matar células de carcinoma de pulmão, principalmente as células do tipo NSCLC, por estas conterem maior concentração desta enzima. Esta observação abre perspectivas para novas estratégias para a quimioterapia seletiva de alguns tipos de câncer, como o de pulmão, próstata e de pâncreas. Seria a mesma abordagem da quimioterapia da doença de Chagas, na qual se sabe que o estresse oxidativo comanda a morte do parasita. ${ }^{45}$

O uso combinado de $\beta$-lapachona com fármacos que atuam por diferentes mecanismos de ação pode ser uma boa alternativa para a quimioterapia do câncer. A combinação de $\beta$-lapachona com taxol, fármaco antineoplásico, tem se mostrado uma associação efetiva contra tumores humanos de ovário e próstata. A associação destas duas substâncias pode vir a ser usada no tratamento de alguns tipos de câncer. ${ }^{46} \mathrm{~A}$ notícia auspiciosa é que a $\beta$-lapachona encontra-se em fase clinica II, sob o código ARQ501, em combinação com a gemcitabina (13), em uma formulação com hidroxipropil- $\beta$-ciclodextrina (HP $\beta C D$ ) (14), para o tratamento do câncer de pâncreas (Figura 7). ${ }^{47}$ 
Ferreira, S. B. et al.

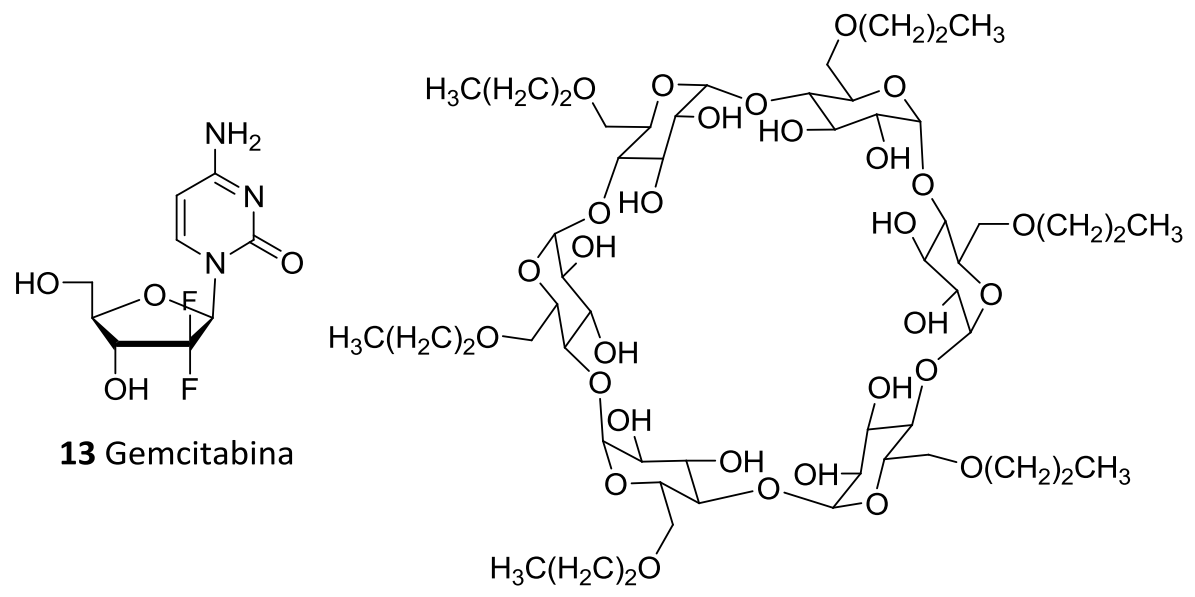

14 Hidroxipropil- $\beta$-ciclodextrina

Figura 7. Estruturas da gemcitabina e hidroxipropil- $\beta$-ciclodextrina

A $\beta$-lapachona (2) foi preparada pela primeira vez, em 1892, a partir do lapachol (1) por Hooker. ${ }^{48}$ Desde então os protocolos comumente utilizados para a síntese da $\beta$-lapachona são baseados na ciclização catalisada por ácido do lapachol, o qual é obtido do cerne das árvores conhecidas como Lapacho (ipê roxo), ou sintetizado a partir da 2-hidroxi-1,4- naftoquinona (Lausona, Esquema 2). ${ }^{49-51} \mathrm{O}$ lapachol é fácilmente extraído da serragem da madeira de várias espécies de ipês brasileiros. Há no Brasil c.a. 46 tipos de madeiras comerciais conhecidas como "ipês" (Tabebuia sp), como por exemplo o ipê branco e o ipê roxo. (Figura 8$).{ }^{13}$

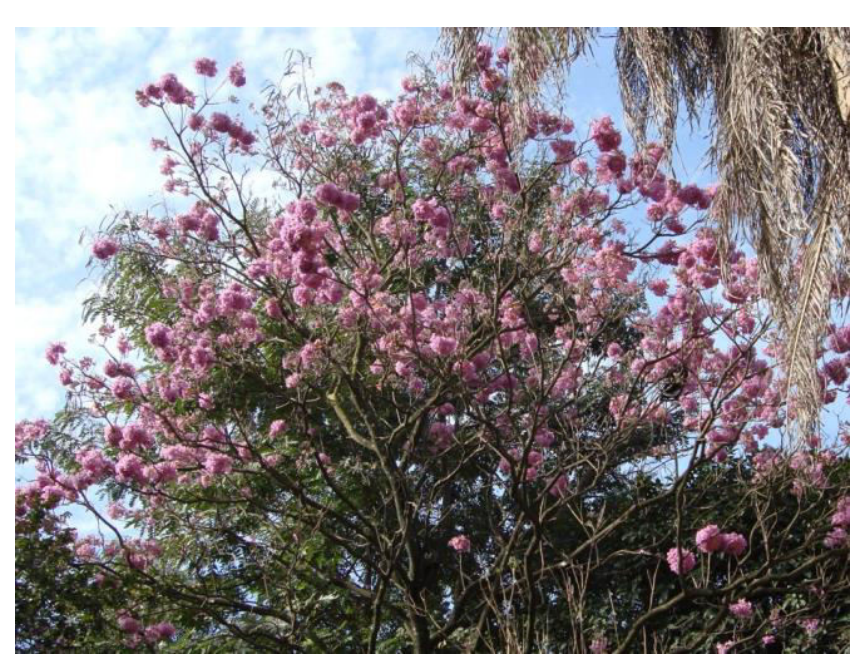

Ipê Roxo

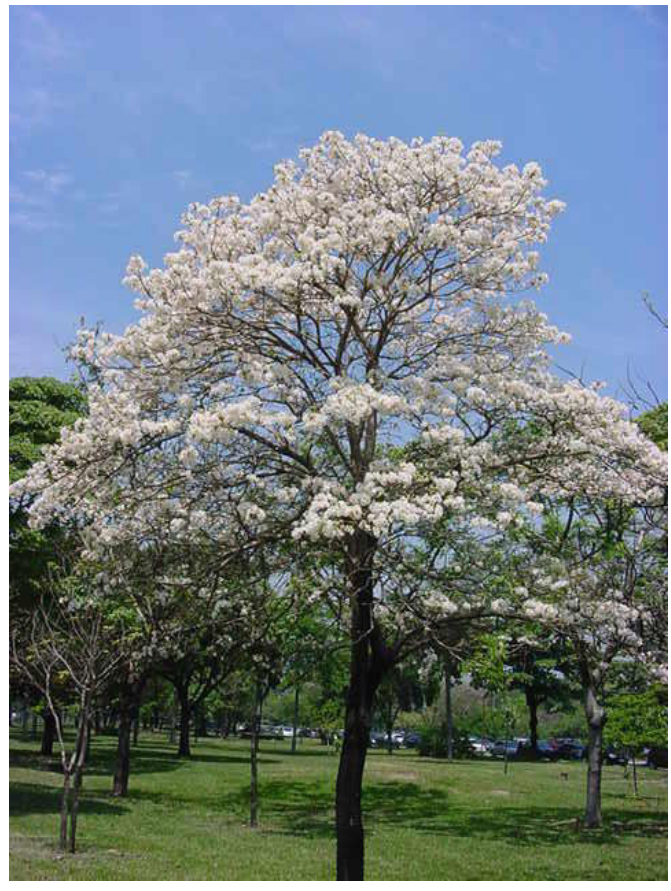

Ipê Branco

Figura 8. Ipês roxo e branco no campus da UFRJ (Fotos cedidas pela Dra. Kelly Gallan e Maria do Carmo F. Pinto, NPPN, UFRJ)

Outro processo utilizado para a síntese da $\beta$ lapachona é a reação eletrocíclica in situ do tipo tandem-Knoevenagel de fenóis, ou a reação da lausona com aldeídos $\alpha, \beta$-insaturados, sob condições de catálise ácida. As desidro-lapachonas obtidas ${ }^{52}$ são hidrogenadas e convertidas no composto $\beta$-lapachona por isomerização em meio ácido. ${ }^{53,54}$ Os rendimentos globais para estes processos variam entre $3-48 \%$. 


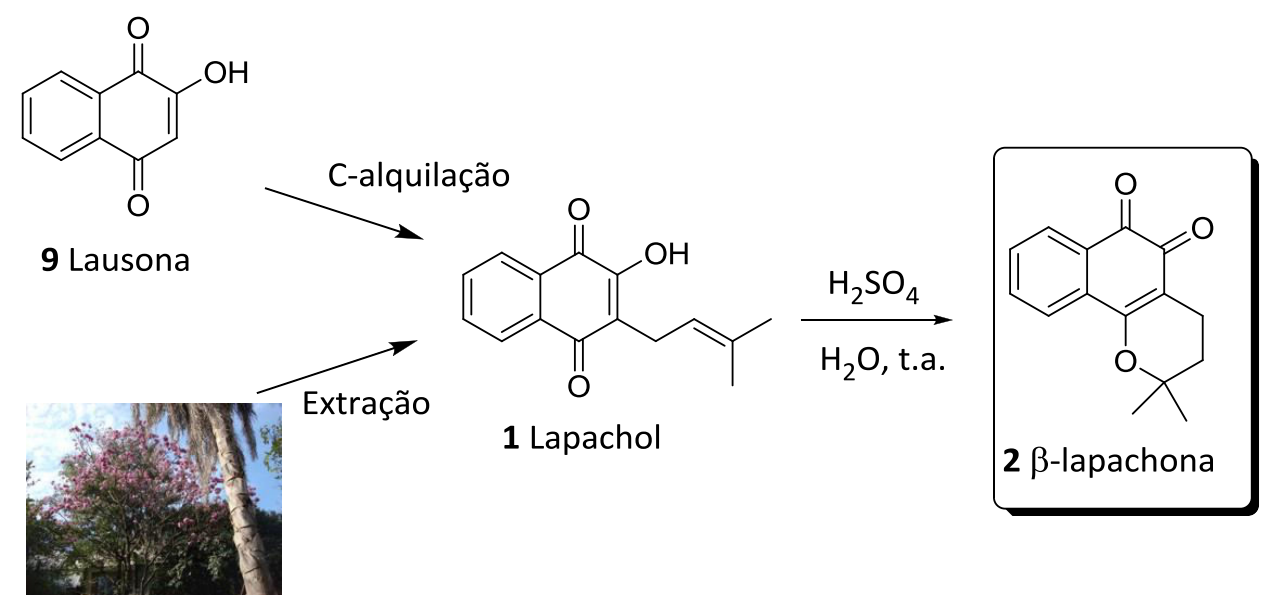

Ipê roxo

Esquema 2. Síntese da $\beta$-lapachona a partir do lapachol por catálise ácida

Recentemente, Ferreira e colaboradores descreveram a síntese da $\beta$-lapachona através de uma metodologia de baixo custo, em uma única etapa em bom rendimento, partindo de reagentes comerciais. 0 mecanismo da reação passa pelo intermediário o-QM (15) formado através da reação da lausona (9) com paraformaldeído (16). A o-QM é capturada in situ pelo isobutileno (17) levando a uma mistura de 1,2- piranonaftoquinona ( $\beta$-lapachona) e 1,4piranonaftoquinona ( $\alpha$-lapachona). A mistura ao ser tratada com ácido sulfúrico concentrado, se converte no produto desejado 2, em $60 \%$ de rendimento. Esta metodologia se mostrou mais eficiente do que as rotas descritas na literatura para a preparação de $\beta$ lapachona (Esquema 3). ${ }^{55}$

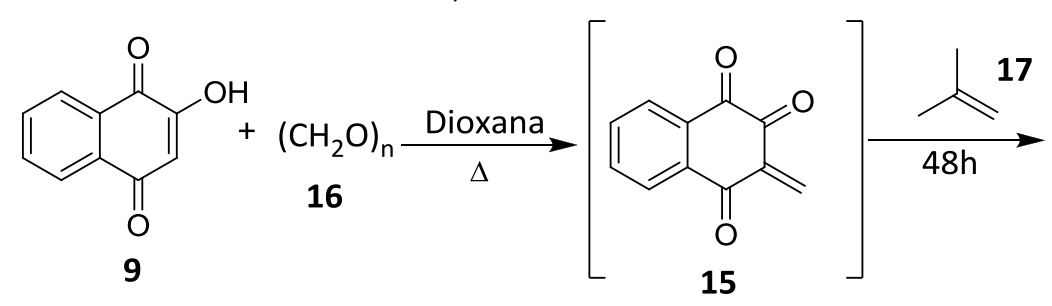<smiles>[Z20]C1(C)CCC2=C(O1)c1ccccc1C(=O)C2=O</smiles>

Esquema 3. Síntese da $\beta$-lapachona em uma etapa a partir da lausona

\section{Modificações nas carbonilas da $\beta$ - lapachona}

Devido ao efeito microbicida e a sua fácil obtenção a partir de fontes naturais e, mais recentemente, ao desenvolvimento de novas rotas sintéticas, a $\beta$ lapachona se tornou uma estrutura privilegiada para a química medicinal. Os químicos medicinais exploram principalmente a reatividade das suas carbonilas quinônicas frente a diversos agentes nucleofílicos, produzindo derivados monossubstituídos em C- 6 ou heterociclos como naftoimidazóis, nafto-oxazóis, dentre outros grupos.

Na busca de novos análogos da $\beta$-lapachona (2) muitas modificações podem ser feitas em sua estrutura. Em relação às carbonilas ou sistema naftoquinônico, dois tipos de modificações podem ser realizadas: modificação seletiva na carbonila C-6 (derivados monossubstituídos) (18) ou reação nas duas carbonilas formando outro anel (carbocíclico ou heterociclo) (19) (Figura 9). 
Ferreira, S. B. et al.<smiles></smiles>

Derivado monossubstituído 18<smiles>CC1(C)CCC2=C(O1)c1ccccc1C(=O)C2=O</smiles>

$\beta$-Lapachona 2

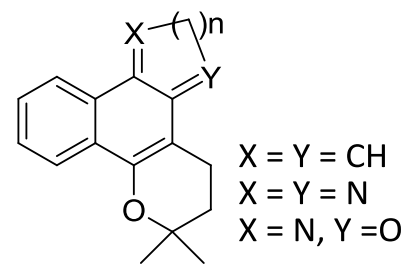

Derivado dissubstituído 19

Figura 9. Possíveis alternativas de modificações estruturais nas carbonilas da $\beta$-lapachona

3.1. Reações de mono adição no sistema naftoquinônico

Na Figura 10 estão mostrados diversos produtos de que foram modificados na carbonila em C- 6 da $\beta$ lapachona descritos na literatura. Pode-se observar que esta posição é mais reativa frente à nucleófilos. Ferreira e colaboradores na busca de fatos para esclarecer a razão da maior seletividade da carbonila C-6, como as densidades de carga das carbonilas, realizaram cálculos de parâmetros estruturais pelo método $a b$ initio (Método Hartree-Fock) e observaram que existe uma planaridade entre os anéis $A$ e $B$, e que $O$ anel $C$ está numa conformação meia-cadeira. Os valores de densidade de carga nas carbonilas C-5 e C-6 foram calculados em +0,472 e $+0,484$, respectivamente, indicando que nucleófilos atacam preferencialmente C-6, apesar da diferença de carga ser pequena, corroborando com os dados experimentais observados. $^{22}$

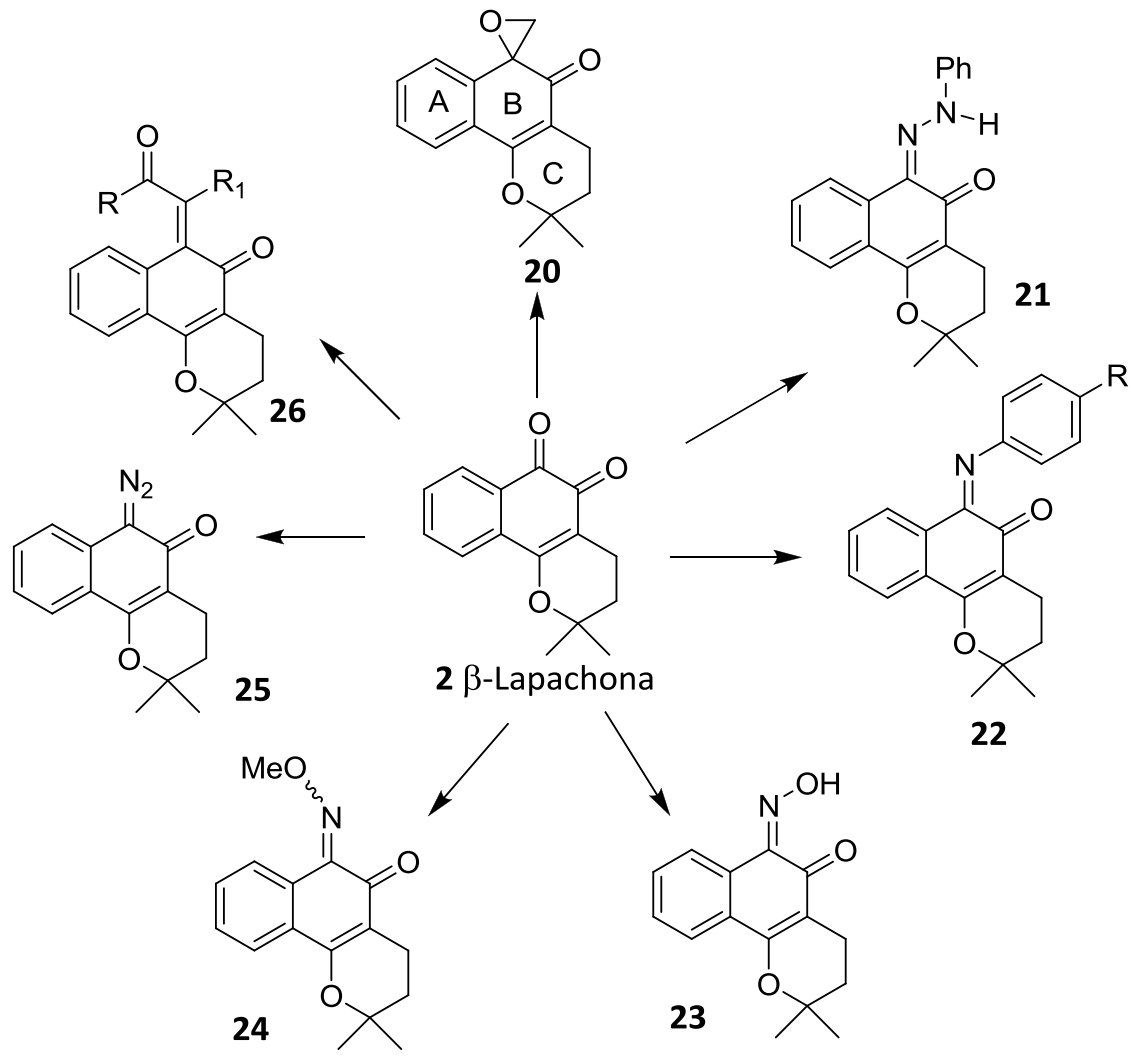

Figura 10. Derivados monossubstituídos da $\beta$-lapachona

O oxirano 20 (Figura 10) foi o primeiro derivado monossubstituído preparado por Pinto e colaboradores, em 1977 , a partir da $\beta$-lapachona. ${ }^{56}$ Esta substância foi obtida através da reação da $\beta$ lapachona (2) com diazometano em éter, com a finalidade de se obter compostos que pudessem inibir topicamente a penetração de cercárias do Schistosoma mansoni em camundongos. Esta substância apresentou atividade de proteção $50 \%$ menor do que o lapachol (1) e do que da própria $\beta$ - 
lapachona (2). Neste trabalho não foram descritos dados espectroscópicos e, portanto, não foi confirmada em qual carbonila ocorreu a adição de diazometano. Com o intuito de sintetizar e avaliar derivados oxirânicos da $\beta$-lapachona (2) contra o
Trypanossoma cruzi, Ferreira e colaboradores prepararam este derivado oxirânico (20) e diversos outros como, por exemplo, o derivado oxirânico da $\alpha$ lapachona (27, Esquema 4). ${ }^{57,58}$

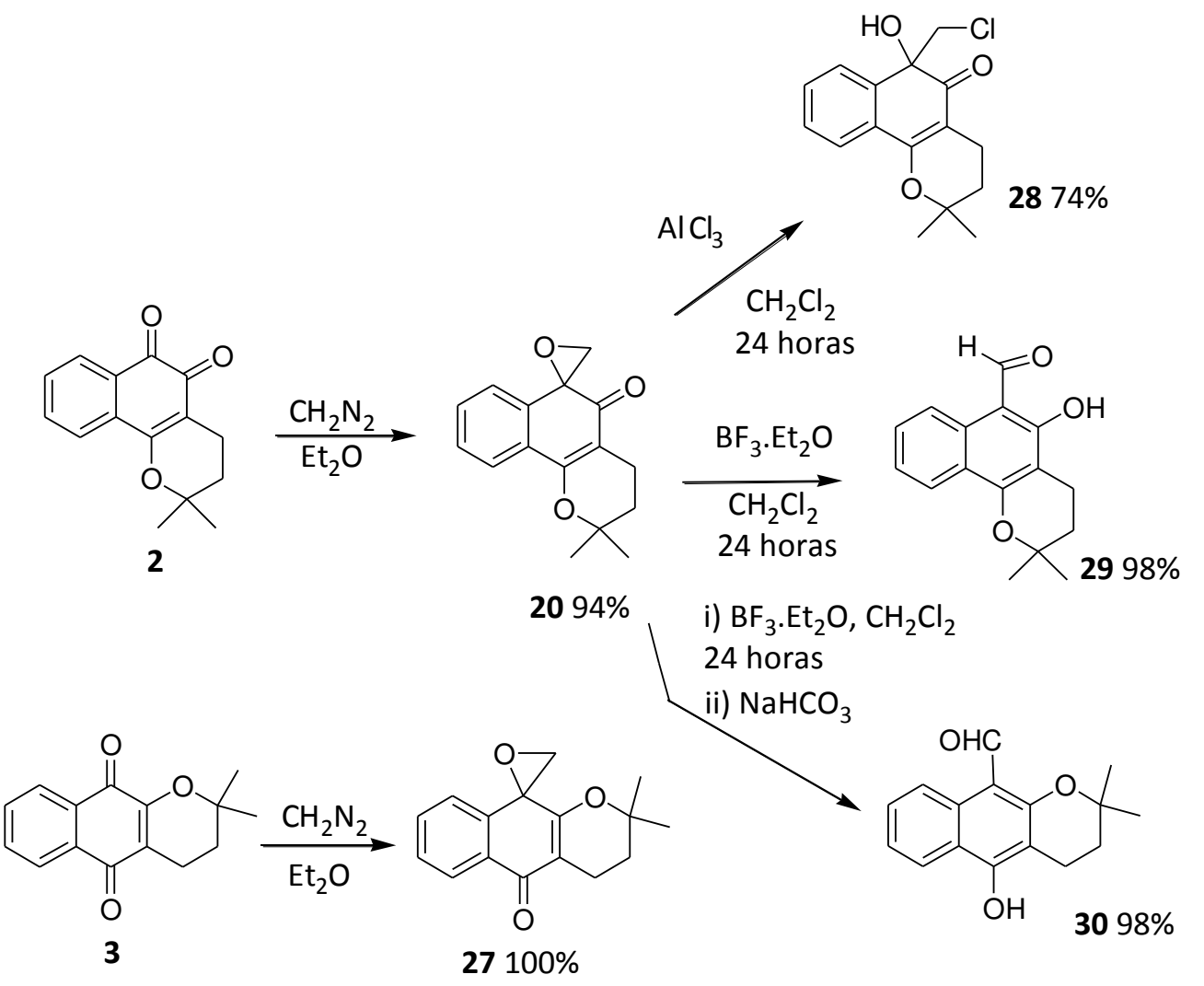

Esquema 4. Preparação de oxiranos e derivados a partir da $\alpha$ - e $\beta$-lapachonas

O derivado oxirânico da $\beta$-lapachona (20) (Esquema 4) apresentou atividade tripanocida $\left(\mathrm{IC}_{50} 12\right.$ $\mu \mathrm{M})$ menor do que a da $\beta$-lapachona $\left(2, \mathrm{IC}_{50} 0,9 \mu \mathrm{M}\right)$, e também apresentou menor citotoxicidade. Como o núcleo quinonoídico foi modificado com a introdução do anel oxirânico na carbonila $C-6$, isso afetou a formação de radicais livres e espécies reativas de oxigênio. Desta série, o derivado oxirânico que apresentou maior atividade tripanocida foi $\mathbf{2 7} \mathrm{com}$ um $\mathrm{IC}_{50}$ de $1,3 \mu \mathrm{M}$, mostrando-se muito mais ativo que a $\alpha$-lapachona $\left(3, \mid \mathrm{IC}_{50}>50 \mu \mathrm{M}\right)$, sem apresentar citotoxicidade para células de mamíferos.

A presença do centro redox das quinonas é descrita na literatura como importante para a atividade antiproliferativa contra $T$. cruzi. Este estudo demonstrou que $\mathrm{o}$ anel oxirano associado às naftoquinonas, constitui uma nova classe de compostos com boa atividade tripanocida e com baixa citotoxicidade para células de mamíferos. Apesar de apresentar propriedades eletrônicas totalmente diferentes, $\mathbf{2 7}$ mostrou-se letal contra a forma tripomastigota do $T$. cruzi para cepas $Y$ e colombianas ( $97 \%$ e $84 \%$, respectivamente), o que indica uma atuação em diferentes mecanismos fisiológicos. ${ }^{59}$ Esta substância é um potencial candidato para quimioterapia da doença de Chagas, uma vez que apresenta atividade tripanocida com baixo perfil de citoxicidade para células humanas.

Outros derivados com modificações no sistema naftoquinônico foram obtidos em altos rendimentos a partir dos oxiranos, por reação de abertura do

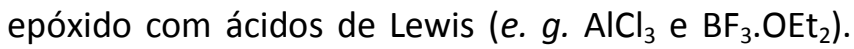
As substâncias 28, $\mathbf{2 9}$ e $\mathbf{3 0}$ foram obtidas em bons rendimentos. Até o momento não há relatos sobre possíveis atividades biológicas destes derivados.

Como seria esperado, a $\beta$-lapachona (2) deveria reagir com outros agentes nucleofílicos principalmente na carbonila C-6. Desta forma, na busca de derivados imínicos mais citotóxicos, Di Chenna e colaboradores, ${ }^{60}$ relataram a síntese regiosseletiva de monoariliminas derivadas da $\beta$ -

Rev. Virtual Quim. |Vol 2| |No. 2| |140-160| 
lapachona (31a-d). Os produtos foram obtidos através do tratamento de $\mathbf{2}$ com pequeno excesso de arilaminas (1,15 eq.) na presença de excesso de trietilamina/tetracloreto de titânio (4:1) (Esquema 5). A imina formada ocorre exclusivamente na posição 6 , formando o diastereoisômero $Z$, cuja estrutura foi determinada por difração de raios $X$. Os ensaios in vitro para citotoxidade, num painel de 12 culturas de células cancerígenas humanas, mostraram diminuição do crescimento celular similar a da $\beta$-lapachona (2). Porém, a fenilimina $31 \quad\left(\mathrm{Gl}_{50} \quad 0,20 \mu \mathrm{M}\right)$, a $\quad p$ metilfenilimina $32 \quad\left(\mathrm{Gl}_{50} \quad 0,19 \quad \mu \mathrm{M}\right)$ e $\quad$ a $p$ metoxifenilimina $33\left(\mathrm{Gl}_{50} 0,096 \mu \mathrm{M}\right)$ foram altamente ativas e seletivas para células tumorais de mama MDA-MB-435. A $p$-nitrofenilimina $\mathbf{3 4}$ apresentou pior desempenho que a $\beta$-lapachona contra todos os tipos células tumorais (Esquema 5).

Boothman e colaboradores mostraram que a $\beta$ lapachona é bioativada por dois elétrons transferidos pela enzima $\mathrm{NAD}(\mathrm{P}) \mathrm{H}$ : quinona oxirredutase, (NQO1; EC 1.6.99.2). Como as enzimas NQO1 reduzem o sistema quinoidal, não seria esperado que derivados monoarilimínicos 31a-d fossem substratos para NQO1 como é a $\beta$-lapachona, e nem se esperava que fossem matar células cancerígenas humanas em tecidos ricos em NQ01. Então a hipótese mais razoável era a de que estas bases de Schiff 31a-d fossem convertidas a $\beta$-lapachona através de uma hidrólise espontânea. Boothman e colaboradores mostraram que as taxas de hidrólise dos derivados imínicos da $\beta$-lapachona variam em função do poder retirador de elétron dos substituintes na posição para do anel aromático. Estes derivados de $\beta$-lapachona são pró-drogas potencialmente úteis para a terapia contra tumores humanos com elevados níveis de NQO1. ${ }^{45}$

Ferreira e Pinto estudaram a reação de $\mathbf{2}$ com o cloridrato da fenil-hidrazina e observaram a formação da 6-fenil-hidrazona (21) e da 5-fenil-hidrazona (35) da $\beta$-lapachona em $75 \%$ e $3 \%$ de rendimento, respectivamente. Estas substâncias foram caracterizadas por espectroscopia e análises de difração de raios $\mathrm{X}$. Por RMN de ${ }^{1} \mathrm{H}$ e UV-visível foi possível observar que a forma hidrazo predomina tanto em solução como no estado sólido. ${ }^{61}$ Mais recentemente, Renou e colaboradores realizaram a preparação de monoaril-hidrazonas da $\alpha$-lapachona e avaliaram suas propriedades antineoplásicas em células malignas cedidas por pesquisadores do Instituto Nacional do Câncer nos Estados Unidos da América ( $\mathrm{NCl}$, do inglês, National Cancer Institute). ${ }^{62} \mathrm{~A}$ oxima $(\mathbf{2 3})^{63}$ e a metiloxima $(\mathbf{2 4})^{64}$ também foram obtidas com a mesma regiosseletividade. $O$ derivado metiloxima (24) foi utilizado para a síntese de derivados oxazinonas potencialmente anti- inflamatórios e antioxidantes.

Ferreira e colaboradores relataram a síntese de derivados diazo, em metanol, de $p$-toluenossulfonilhidrazina com diversas nafto-quinonas. $\beta$-lapachona (2) formou apenas um diazo-naftalenona (25) com rendimento de $98 \% .{ }^{65,66}$ Deve-se ressaltar a formação do subproduto 36 oriundo da disproporcionamento do ácido p-toluenossulfínico formado na reação de decomposição da hidrazona. A confirmação da estrutura do 6-diazo-2,2-dimetil-2,3,4,6-tetra-hidro$2 \mathrm{H}$-benzo[h]cromen-5-ona (25) foi realizada por difração de raios $X$ e ressonância magnética nuclear de $\mathrm{N}^{15}$. Em particular, esta substância foi testada contra o $T$. cruzi e diversas bactérias, mas não demonstrou possuir nenhum tipo de atividade, porém em termos de síntese orgânica pode ser um intermediário valioso para a obtenção de outros derivados, devido a reatividade do grupo diazo. ${ }^{67}$

As orto-quinonas metídio (o-QMs) são intermediários altamente reativos frente à nucleófilos ou eletrófilos e, normalmente, com tempo de vida curto. Estas substâncias contendo uma unidade metilidênica conjugada a uma carbonila exocíclica são muito reativas, e se tornaram intermediários de ampla aplicabilidade em síntese orgânica. Vários métodos sintéticos têm sido desenvolvidos para sua obtenção. As o-QMS estão envolvidas em diversos processos biológicos inibindo enzimas como fosfodiesterases e fazendo ligações cruzadas com o DNA. Sua eletrofilicidade perante aminas, tióis, água, DNA, aminoácidos e peptídeos tem sido utilizada como estratégia para o desenvolvimento de fármacos anticâncer como a mitomicina $\mathrm{C}$.

Ferreira e colaboradores descreveram recentemente a síntese de $o$-QMs estáveis derivadas da $\beta$-lapachona (2, Esquema 6). ${ }^{68} \mathrm{~A}$ transformação da $\beta$-lapachona (2) em $o$-QMs pode ser uma importante estratégia sintética para a transformação em outros compostos biologicamente ativos. A síntese das 0 QMs (37a-e) foi realizada por condensação aldólica, catalisada por iodo, da $\beta$-lapachona (2) com diversas cetonas na carbonila 6 . Duas dessas $0-\mathrm{QM}$ foram convertidas em o-QMs alquil fluoradas (38a-b) que também se mostraram estáveis (Esquema 6). Até o presente momento nenhuma atividade biológica foi relatada para estas 0 -QMs.

3.2. Reações de formação de heterociclos no sistema naftoquinônico

O grupo que mais explorou as reações de formação de heterociclos no sistema quinonoídico da 
$\beta$-lapachona foi o de Ventura Pinto e colaboradores. Diversos derivados contendo os sistemas imidazólico, oxazólico, fenoxazínico, indólico, dipirânico e ciclopentênico foram sintetizados e avaliados frente a alguns alvos farmacológicos.

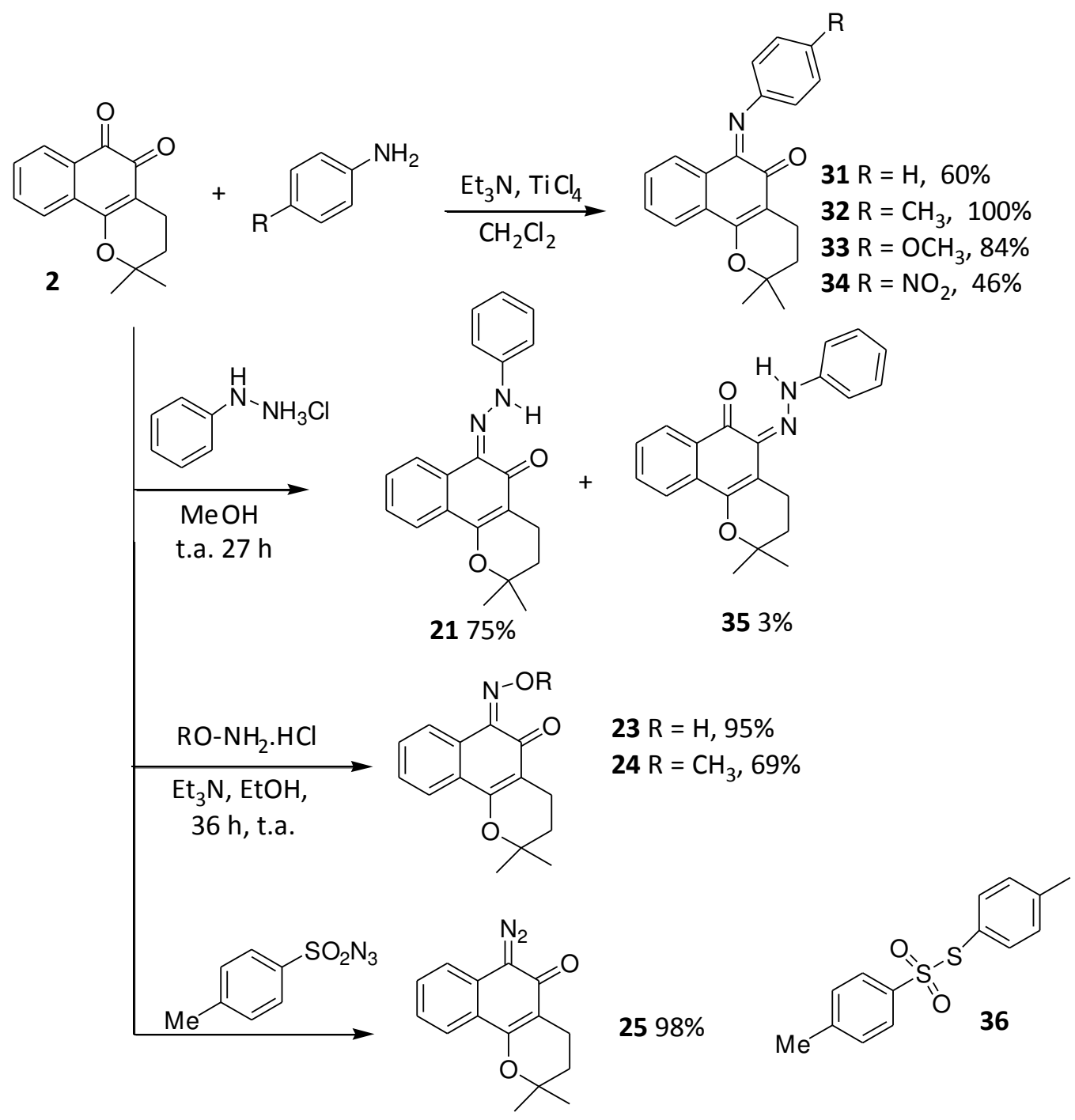

Esquema 5. Sínteses de ariliminas e hidrazonas da $\beta$-lapachona<smiles>CC1(C)CCC2=C(O1)c1ccccc1C(=O)C2=O</smiles><smiles>[R2]CC([R])=O</smiles><smiles>[R]C(=O)/C([R])=C1/C(=O)C2=C(OC(C)(C)CC2)c2ccccc21</smiles>

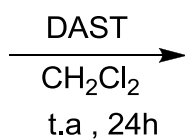

(2)

37a $R_{1}=\mathrm{CH}_{3}, \mathrm{R}_{2}=\mathrm{H}, 80 \%$

37b $R_{1}=R_{2}=C_{3}, 66 \%$

37c $R_{1}=$ ciclopropil, $R_{2}=H, 26 \%$

37d $\mathrm{R}_{1}=\mathrm{CH}_{3}, \mathrm{R}_{2}=\mathrm{CO}_{2} \mathrm{Et}, 36 \%$

37e $\mathrm{R}_{1}=\mathrm{EtO}_{2} \mathrm{CCH}_{2}, \mathrm{R}_{2}=\mathrm{H}, 9 \%$<smiles>[R]C(=C1C(=O)C2=C(OC(C)(C)CC2)c2ccccc21)C([R])([R])[R]</smiles>

38a $\mathrm{R}_{1}=\mathrm{CH}_{3}, \mathrm{R}_{2}=\mathrm{H}$,

$R_{3}=R_{4}=F, 80 \%$

$38 b \mathrm{R}_{1}=\mathrm{R}_{2}=\mathrm{CH}_{3}$

$R_{3}=R_{4}=F, 75 \%$

Esquema 6. Síntese de o-QMs derivadas da $\beta$-lapachona 
As primeiras substâncias heterociclas derivadas da $\beta$-lapachona foram os derivados oxazólicos produzidos por Ventura Pinto e colaboradores. ${ }^{69}$ Estes autores descreveram duas rotas sintéticas para a substância 39 a partir do lapachol ou da própria $\beta$ - lapachona por reação com alquilaminas. Para a rota a partir do lapachol foi postulado um mecanismo envolvendo a participação da forma tautomérica 1,2quinônica do lapachol (Esquema 7).

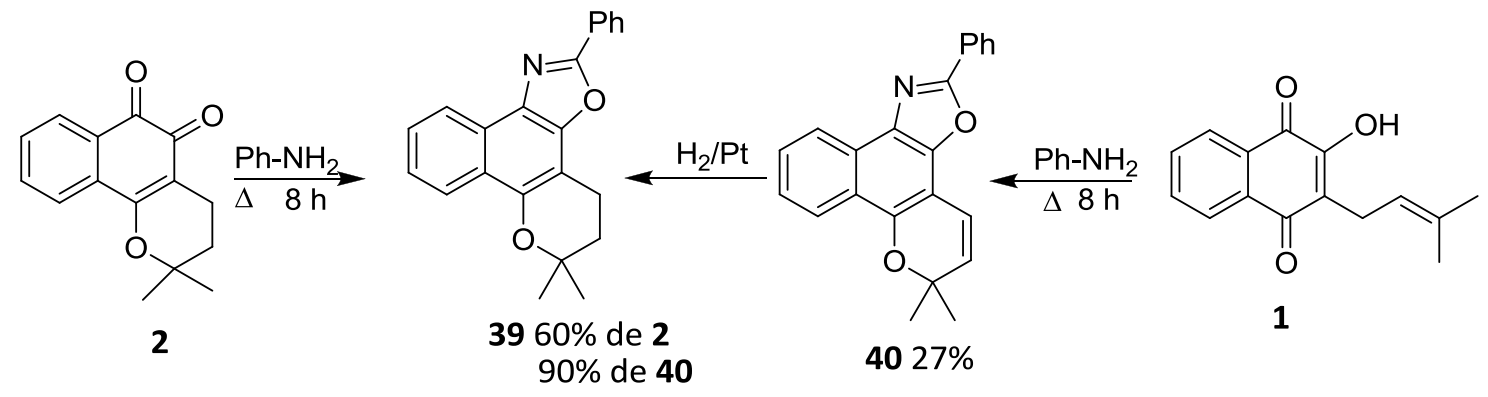

Esquema 7. Síntese de derivados oxazólicos da $\beta$-lapachona

Tendo como alvo o $T$. cruzi, o mesmo grupo desenvolveu novas preparações de derivados oxazólicos e imidazólicos ${ }^{13}$ a partir da $\beta$-lapachona, e de diversas outras 1,2-naftoquinonas. Inicialmente a preparação dos derivados dos sistemas naftoimidazol e naftoxazol foi realizada conjuntamente através da reação da $\beta$-lapachona com aldeídos fenílicos e heterociclos na presença de um sal de amônio, formando a mistura dos dois heterociclos que foram separados em coluna cromatográfica. Foi observado que o tempo de reação era um fator importante na distribuição dos produtos sendo possível preparar seletivamente estes derivados. Em tempos curtos de reação os derivados oxazólicos (41) são formados majoritariamente, enquanto que tempos longos favorecem a formação dos derivados imidazólicos (42a-f). A síntese do oxazol 41e $\left(\mathrm{R}=\mathrm{CO}_{2} \mathrm{Et}\right)$ foi desenvolvida posteriormente pela reação da $\beta$ lapachona com o éster etílico da glicina. ${ }^{70}$ Recentemente, um derivado oxazólico mais simples 41a $(R=H)$ foi sintetizado a partir da reação da oxima com diazometano. ${ }^{71}$ A regio-orientação foi confirmada por difração de raios $X$ (Esquema 8).

O naftoxazol 41a foi mais ativo contra o T. cruzi do que o cristal violeta utilizado como referência. A introdução do grupo aromático no núcleo oxazólico mostrou influência marcante sobre a atividade tripanocida. O composto $\mathbf{4 1 b}$ com um grupo fenil não substituído e o composto 41c com um grupo metilenodióxi acoplado ao anel aromático aumentou a atividade em relação ao cristal violeta. Diversos naftoimidazóis foram sintetizados e avaliados contra diversas formas do $T$. cruzi. ${ }^{32}$ De uma forma geral estes derivados foram mais ativos que os naftoxazóis. Dentre os derivados sintetizados três apresentaram alta atividade tripanocida contra as três formas do $T$. cruzi, a saber, 42a, 42f e 43, sendo que 42a é 10,6 vezes mais ativo do que a $\beta$-lapachona. Neste aspecto, 42a foi investigado sobre sua atividade contra as formas tripomastigotas, epimastigotas e amastigotas do $T$. cruzi. Os autores do trabalho sugerem que a alta atividade dos naftoimidazóis contra o $T$. cruzi, especialmente de 42a, quando comparado a de outras classes de compostos sintetizados a partir da $\beta$-lapachona pode estar relacionada com a base imidazol, grupo também presente em várias substâncias com atividade tripanocida, como o benzonidazol, pois 42a não é capaz de gerar radicais livres, como outras naftoquinonas (Figura 11). ${ }^{72}$ 


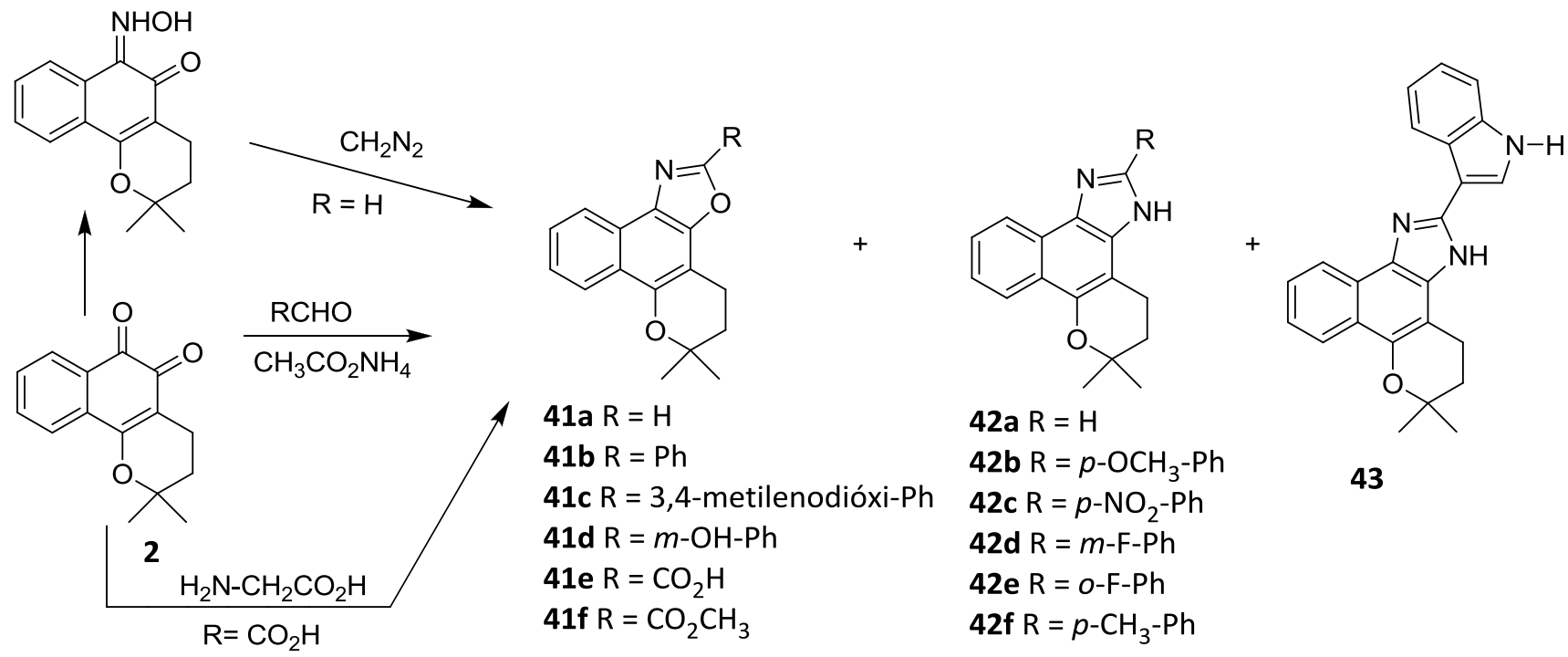

Esquema 8. Esquema de síntese dos sistemas naftoimidazol e naftoxazol<smiles>CC1(C)CCc2c(c3[nH]cnc3c3ccccc23)O1</smiles>

$42 a$<smiles>Cc1ccc(-c2nc3c([nH]2)c2c(c4ccccc43)OC(C)(C)CC2)cc1</smiles>

43
Figura 11. Naftoimidazóis com ação tripanocida significativa

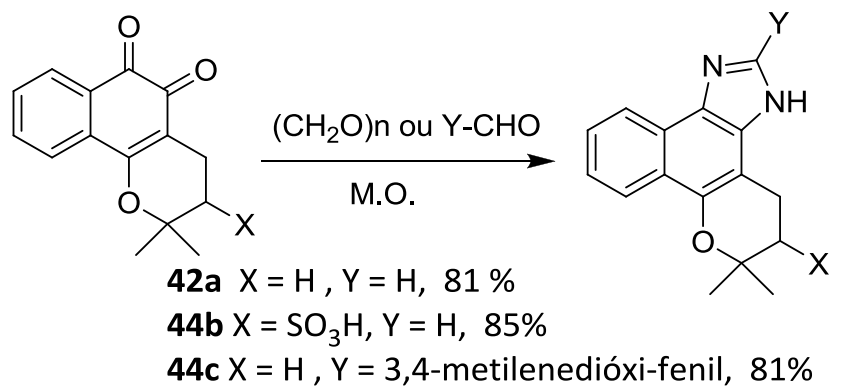

Esquema 9. Síntese de naftoimidazóis promovida por micro-ondas
Nicolaides e colaboradores relataram que a adição do trifenil-fosforano 45 a temperatura ambiente, durante uma hora, em diclorometano seco, leva a formação de derivados cumarínicos das $\beta$-lapachona (2) e da 3-hidroxi $\beta$-lapachona (46) (Esquema 10). ${ }^{64} \mathrm{~A}$ formação destas substâncias pode ser racionalizada através da reação de um equivalente do ilídeo na carbonila 6 das lapachonas, seguida da adição de um segundo equivalente do ilídeo (adição de Michael) formando os intermediários 47a e 47b, que após lactonização resultam nos derivados cumarínicos $48 \mathrm{a}$ e 48b. Através desta reação foram obtidas as substâncias 48a (rendimento não relatado) e 48b (74\%). Foram realizados ensaios para atividade antiinflamatória in vitro e in vivo, e antioxidante. $\mathrm{O}$ ensaio anti-inflamatório in vitro consistiu na inibição da tripsina, e o in vivo na inibição da formação de edema de pata de rato induzido por carragenina. $O$ ensaio antioxidante foi feito pelo método do descoramento do radical DPPH. O DPPH na forma radicalar apresenta alta absorbância a $517 \mathrm{~nm}$. Após a reação com sequestrantes de radicais livres, a absorbância diminui, e desta forma mede-se a capacidade sequestrante de radicais da substância em questão. Os compostos testados foram reativos frente ao DPPH e a tripsina, em graus diversos, e também foram capaz de inibir a formação de edema pata de rato em 48,7-58,9\%. 
<smiles>[R]C1CC2=C(OC(C)(C)C1)c1ccccc1C2=O</smiles>

$2 \mathrm{Ph}_{3} \mathrm{P}=\mathrm{CHCOOEt}$

45

$$
2 \mathrm{R}=\mathrm{H}
$$$$
46 \mathrm{R}=\mathrm{OH}
$$

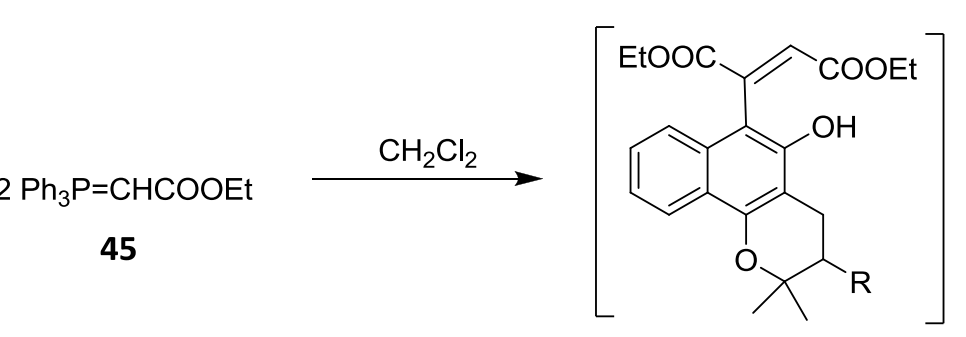

47a $\mathrm{R}=\mathrm{H}$ 47b $\mathrm{R}=\mathrm{OH}$<smiles>[R]C1Cc2c(c3ccccc3c3c(C(=O)OCC)cc(=O)oc23)OC1(C)C</smiles>

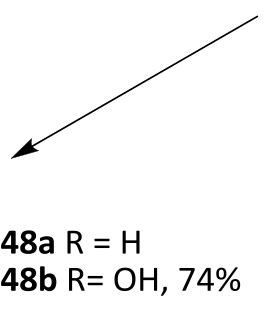

Esquema 10. Síntese de derivados cumarínicos

Nicolaides e colaboradores relataram a síntese de $2 H$-1,4-benzoxazinas derivadas das $\beta$-lapachona (2) e da 3-hidroxi $\beta$-lapachona (46) (Esquema 11$)^{74}$ através do tratamento das respectivas lapachonas com cloridrato de metóxi-amina, em metanol, que levou a formação de uma mistura isomérica de 0 metiloximas, em $69 \%$ de rendimento. A mistura foi tratada com fenilacetato de metila a $180^{\circ} \mathrm{C}$ por trinta minutos, resultando na oxazina $50 a$, em $21 \%$ de rendimento a partir de $\beta$-lapachona. No caso da 3hidroxi $\beta$-lapachona (46) foram obtidos a oxazina $50 \mathrm{~b}$ e o oxazol 51b em 37 e $11 \%$ de rendimentos, respectivamente. A oxazina 50 a foi obtida em $40 \%$ de rendimento. Tanto as oxazinas como o oxazol apresentaram significativa atividade anti-inflamatória. Apenas a oxazina 50a apresentou atividade antioxidante.

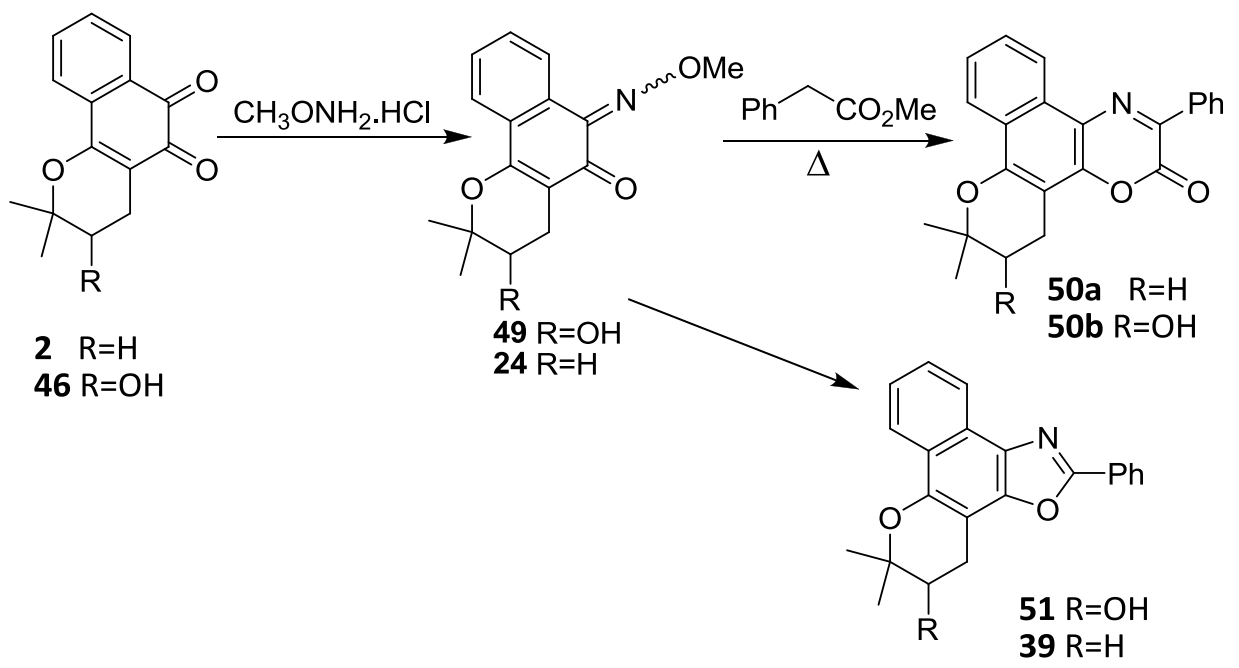

Esquema 11. Síntese de oxazinas e oxazol

Neder e colaboradores ${ }^{75}$ descreveram a reação entre a $\beta$-lapachona (2), e outras orto-naftoquinonas similares, com 2-mercaptoetanol na presença de $\mathrm{BF}_{3} . \mathrm{Et}_{2} \mathrm{O}$ (Esquema 12). Este trabalho evidencia que a $\beta$-lapachona (2) tem uma forte afinidade por sítios sulfidrílicos, comuns em superfícies de macromoléculas biológicas. Recentemente, Goulart e colaboradores, ${ }^{77}$ com base nesta hipótese, mostraram que na redução eletroquímica da $\beta$-lapachona na presença dsDNA e ssDNA (DNA dupla fita e DNA fita simples) não houve danos diretos no DNA, indicando que a sua atuação é sobre as DNA topoisomerases. A fim de verificar a participação dos resíduos de Lcisteína das topoisomerases no processo de interação $\beta$-lapachona-topoisomerases, foi estudada a voltametria cíclica conjunta da $\beta$-lapachona com a Lcisteína e o 2-mercaptoetanol. Os resultados indicaram efeitos dependentes da concentração, indicando uma possível adição tipo 1,2 e 1,4 do grupo tiol na $\beta$-lapachona (2), reforçando a hipótese de Neder. ${ }^{75}$ 


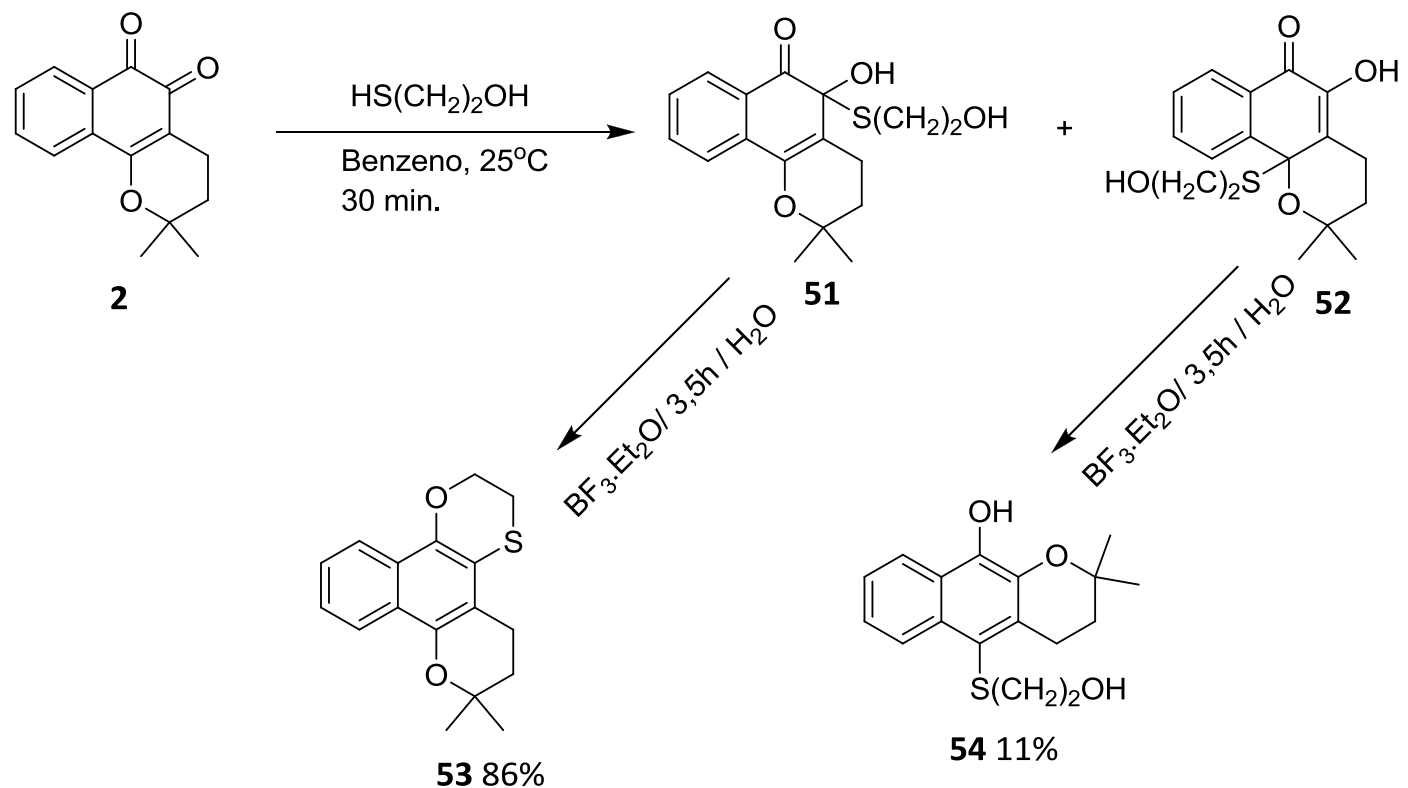

Esquema 12. Produtos de adição e condensação da $\beta$-lapachona com mercaptoetanol

A partir de $\beta$-lapachona há diversos métodos para a preparação de fenazinas. Estas são substâncias heterocíclicas aromáticas isoladas de fontes naturais ou de origem sintética, ${ }^{76}$ que apresentam atividade antibiótica, ${ }^{77-81}$ tripanocida, ${ }^{82}$ antitumoral, antimalárica e antiparasitária (Figura 12).<smiles>CC(=O)c1ccc(O)c2c1=NC1C(O)=C(C)C(O)=CC1N=2</smiles>

55<smiles>COc1ccc(CO)c2nc3cccc(C(=O)NC4=C(O)CCC4O)c3nc12</smiles><smiles>CC(O)c1cccc2nc3c(C(=O)OC4C(O)OC(O)C(O)C4O)cccc3nc12</smiles>

Figura 12. Exemplo de fenazinas isoladas de fontes naturais

A metodologia mais direta para a preparação de fenazinas é a partir da formação de duas iminas entre 1,2-diaminas e orto-quinonas sob catálise ácida. Pinto e colaboradores descreveram a síntese de fenazinas a partir de lapachonas e nor-lapachonas, ${ }^{83}$ em altos rendimentos (Esquema 13). Estas fenazinas foram testadas frente a quatro diferentes cepas de Plasmodium falciparum e comparadas à cloroquina, um antimalárico de referência, tanto in vitro como in vivo. Os grupos de parasitas $\mathrm{BHz} 26 / 86$ (originário de Candeias, Rondônia) e W2 (clone resistente à cloroquina e a mefloquina) se mostraram mais suscetíveis às fenazinas, em particular aquelas

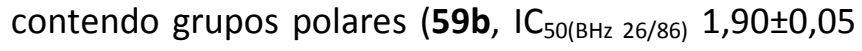

$\mu \mathrm{M}, \quad \mathrm{IC}_{50 \text { (W2) }} 3,04 \pm 0,1$ e $\left.59 \mathrm{e}, \mathrm{I} \mathrm{C}_{50(\mathrm{BHz}} 26 / 86\right) 1,75 \pm 0,02$, $\left.I C_{50\left(W_{2}\right)} 1,67 \pm 0,05\right)$ do que a cloroquina. ${ }^{84}$

Outros trabalhos envolvendo diaminas foram relatados para a produção de pirazinas, ${ }^{85}$ que é o sistema fenazínico sem o anel aromático adicional. ${ }^{86}$ Algumas pirazinas e fenazinas derivadas das lapachonas (Esquema 13) foram avaliadas quanto a sua capacidade de inibição do crescimento de células tumorais por Campillo e colaboradores, que realizaram ensaios de citotoxicidade em linhagens de células leucêmicas promielocíticas humana HL-60 e observaram que a pirazina 60a tem baixa atividade $\left(\mathrm{IC}_{50}>100 \mu \mathrm{M}\right)$ quando comparada com a $\beta$-lapachona $\left(\mathrm{IC}_{50} 0,27 \pm 0.04 \mu \mathrm{M}\right){ }^{87}$ 
Ferreira, S. B. et al.

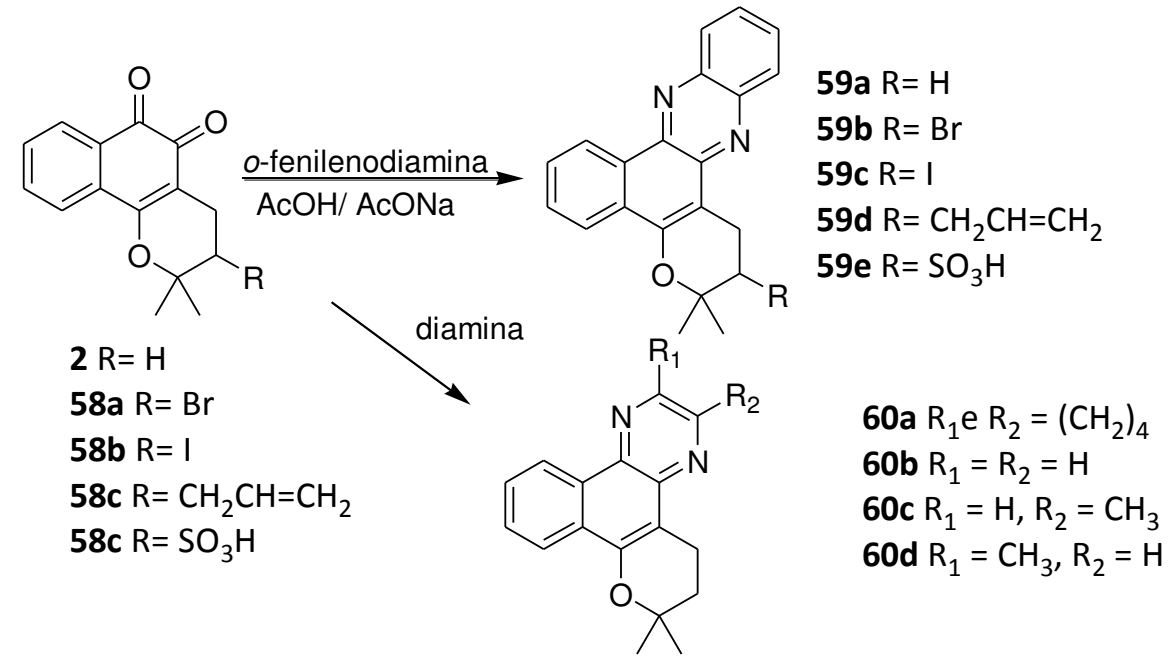

Esquema 13. Síntese de algumas pirazinas e fenazinas a partir de $\beta$-lapachona e derivados

Algumas fenazinas são de grande interesse pois, apresentando alto rendimento quântico de fluorescência, podem ser utilizadas como sondas em sistemas biológicos, exigindo menores concentrações para serem detectadas. Neste sentido, Pinto e colaboradores descreveram a síntese de diversas fenazinas diméricas a partir da $\beta$-lapachona (2) que se mostraram bastantes promissoras em estudos fotoquímicos como potenciais sondas fluorescentes (e. g. 61 e 62, Figura 13). ${ }^{88-90}$ Inicialmente os isômeros cisoide e transoide das $\beta$-nor- e $\beta$-lapachonas foram preparados em rendimentos muito baixos utilizando glicina como agente de amoniação. ${ }^{91}$ Melhores resultados foram alcançados quando a glicina foi substituída por $\mathrm{CH}_{3} \mathrm{CO}_{2} \mathrm{NH}_{4}$ ou $\mathrm{HCO}_{2} \mathrm{NH}_{4}$, em vários solventes e sob diferentes condições. ${ }^{92}$<smiles>CC1(C)CCC2=C(O1)c1ccccc1-c1nc2c2c3c(c4ccccc4c2n1)CCC(C)(C)O3</smiles>

61<smiles>CC1(C)CCc2c(c3ccccc3c3nc4c(nc23)c2c(c3ccccc34)OC(C)(C)CC2)O1</smiles>

62
(Esquema 14) e teve sua estrutura confirmada por difração de raios $X$.

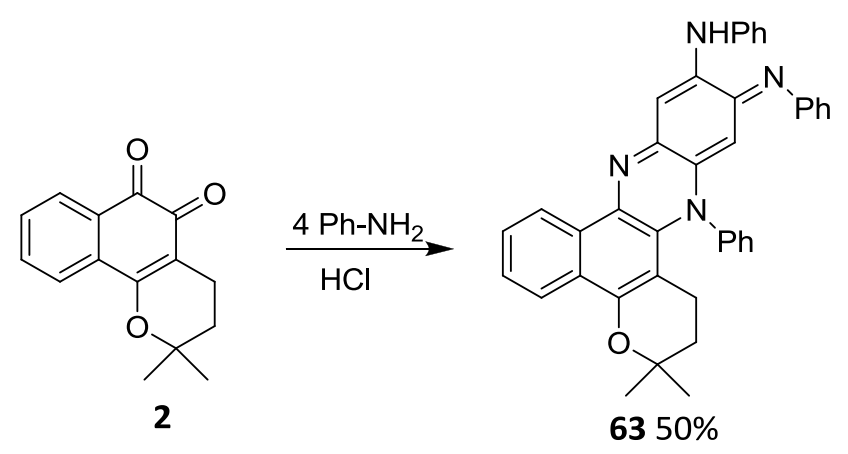

Esquema 14. Preparação da fenazina 63 a partir da $\beta$ lapachona com excesso de anilina

Ferreira e colaboradores desenvolveram uma metodologia geral que envolve reações de lapachonas com sal de aliltrifenilfosfônio, na presença de solução aquosa de $\mathrm{NaOH}$ e clorofórmio. ${ }^{93}$ A reação forma in situ a o-QM intermediária 66, que cicliza para o $2 \mathrm{H}$ cromeno, como mostrado no (Esquema 15). Com esta síntese one-pot seletiva e geral, diversos derivados $2 \mathrm{H}$-cromenos (67a-d, 68a-f e 69a-b) foram obtidos em rendimentos que variaram de 47 a $85 \%$. Nota-se que o ilídeo de fósforo ataca exclusivamente a posição 6 ou a carbonila $\alpha$ mais reativa da orto-naftoquinona.

As características das naftoquinonas em geral com destaque para $\beta$-lapachona e seus derivados relatados aqui neste trabalho sinalizam o quanto ainda há de potencial a ser desenvolvido para esta classe de substância, em vista de estudos químico-sintéticos e farmacológicos. Novos derivados, mais ativos e mais seletivos são temas importantes ainda a serem estudados. Neste âmbito, incluem-se os interesses de diversos grupos de pesquisa no desenvolvimento de 
novos e potenciais compostos contendo o sistema naftoquinônico. Hoje o maior interesse pelas naftoquinonas reside nos seus efeitos indutores na apoptose e na sua ação tripanocida.

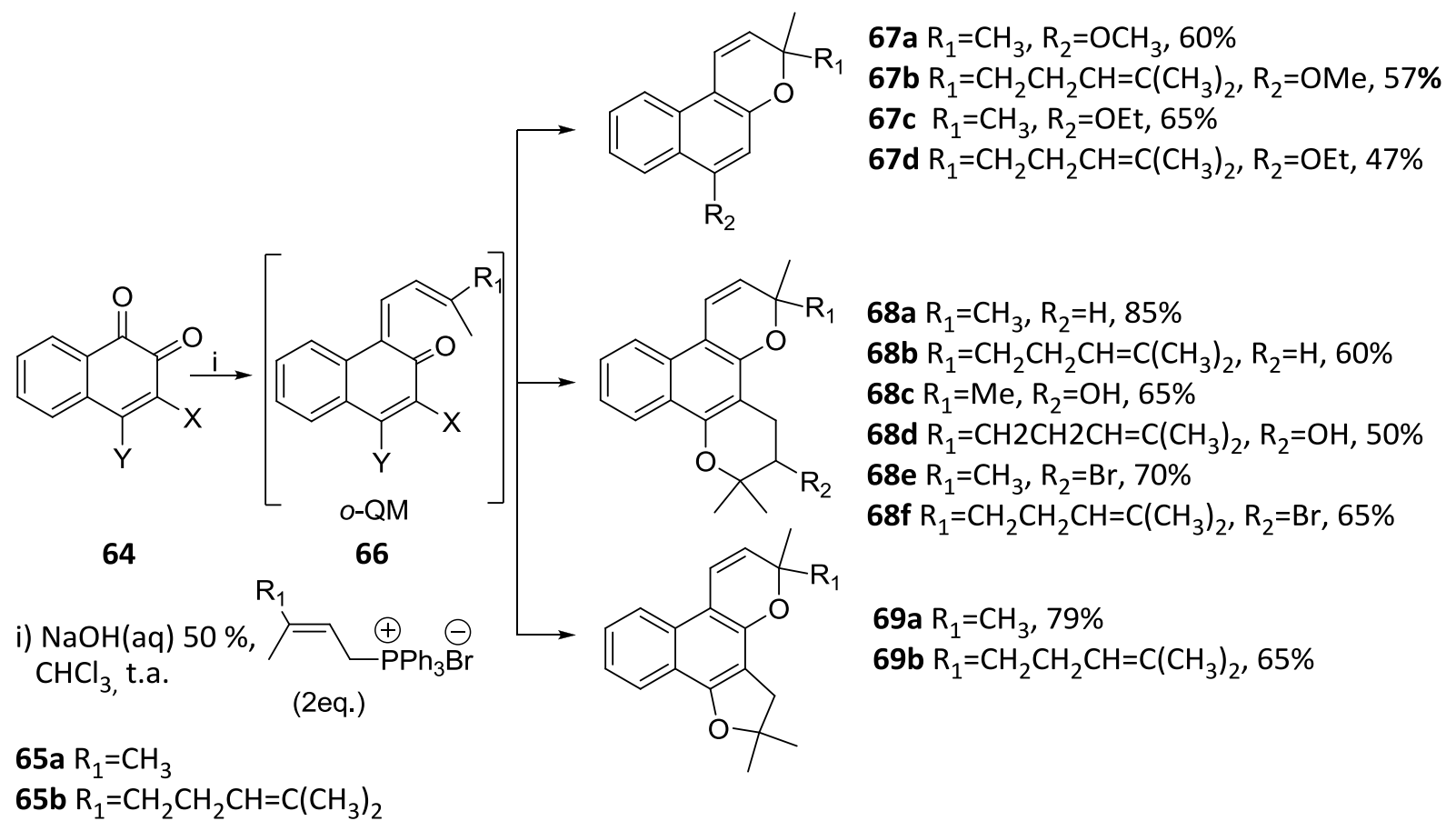

Esquema 15. Síntese de $2 \mathrm{H}$-cromenos por reação de $o$-naftoquinonas com sal de aliltrifenilfosfônio

\section{Comentários finais}

Esta revisão é uma homenagem aos professores e pesquisadores Oswaldo Gonçalves de Lima e Antonio Ventura Pinto pelas suas grandes e importantes contribuições científicas à química e a farmacologia de naftoquinonas. Graças aos trabalhos destes pioneiros, vários pesquisadores brasileiros se dedicam, hoje, aos estudos das naftoquinonas. Não se pode deixar de mencionar que se a $\beta$-lapachona vier a se tornar um fármaco antineoplásico, isto muito se deverá aos brasileiros Gonçalves Lima e Ventura Pinto.

\section{Agradecimentos}

Os autores gostariam de agradecer as valiosas contribuições de todos os pesquisadores citados nesta revisão e a todas as agências que financiam as nossas pesquisas, em particular a FAPERJ, através do financiamento do projeto PRONEX-FAPERJ (E26/171.512/2006) "Síntese e avaliação biológica de naftoquinonas: a busca de novos compostos com atividade antitumoral e antiparasitária", coordenado pelo Prof. Angelo da Cunha Pinto (UFRJ). Agradecemos à Maria do Carmo F. Pinto da UFRJ e a Dra. Kelly Gallan da UFRJ pelas fotos dos ipês gentilmente cedidas e à Profa. Suely Galdino pela foto do Prof. Oswaldo Gonçalves de Lima.

\section{Referências Bibliográficas}

${ }^{1}$ Sítio do Clinical Trials of US National Institutes of Health. Disponivel em: <http://clinicaltrials.gov/ct2/show/NCT00102700>. Acesso em: 13 setembro de 2010.

${ }^{2}$ http://www.usinadeletras.com.br/exibelotexto.php ?cod=39307\&cat=Artigos\&vinda=S. Acesso em: 13 setembro de e 2009.

${ }^{3}$ Carvalho, H. G. Quím. Nova 1995, 18, 309. [Link]

${ }^{4}$ Arnaudon, G. Compt. Rend. 1858, 46, 1152.

${ }^{5}$ Paternó, E. Gazz. Chim. Ital. 1882, 12, 337.

${ }^{6}$ Lima, O. G.; D'Albuquerque, I. L.; Machado, M. P.; Silva , E.; Pinto, G. P. Separata dos Anais da Sociedade de Biologia de Pernambuco 1956, 14, 129.

${ }^{7}$ Sampaio, W. V., Página da editora Usina de Letras. Disponível em: $<$ https://www.usinadeletras.com.br/exibelotexto.php ?cod=39307\&cat=Artigos\&vinda=S>. Acesso em: 13 setembro de 2010.

${ }^{8}$ Santana, C. F.; Lima, O. G.; D'Albuquerque, I. L.; Lacerda, A. L.; Martins, D. G. Rev. Inst. Antibiot. 1968, Rev. Virtual Quim. |Vol 2| |No. 2| |140-160| 
8(1/2), 89.

${ }^{9}$ Rao, K. V.; Mcbride, T. J.; Oleson, J. J. Cancer Res. 1968, 28, 1952. [Link]

10 Li, C. J.; Li, Y. Z.; Pinto, A. V.; Pardee, A. B. Proc. Natl. Acad. Sci. U.S.A., Early Ed. 1999, 96, 13369. [Link]

${ }^{11}$ Li, Y. Z.; Li, C. J.; Pinto, A. V.; Pardee, A. B. Mol. Med. 1999, 5, 232. [PubMed]

${ }^{12}$ Sítio da empresa ArQule. Disponível em: <http://www.arqule.com/>. Acesso em: 13 setembro de 2009.

${ }^{13}$ Silva, M. N.; Ferreira, V. F.; de Souza, M. C. B. V. Quím. Nova 2003, 26, 407. [CrossRef]

${ }^{14}$ Liu, K. C.; Li, J.; Sakya, S. Mini-Rev. Med. Chem. 2004, 4, 1105. [Link]

${ }^{15}$ Asche, C. Mini-Rev. Med. Chem. 2005, 5, 449. [CrossRef] [PubMed]

${ }^{16}$ Santos, A. F.; Ferraz, P. A. L.; Pinto, A. V.; Pinto, M. C. F. R.; Goulart, M. O. F.; Sant'Ana, A. E. G. Int. J. Parasitol. 2000, 30, 1199. [CrossRef] [PubMed]

${ }^{17}$ Dos Santos, A. F.; Ferraz, P. A. L.; De Abreu, F. C.; Chiari, E.; Goulart, M. D. F.; Sant'Ana, A. E. G. Planta Med. 2001, 67, 92. [CrossRef] [PubMed]

${ }^{18}$ Barbosa, T. P.; Camara, C. A.; Silva, T. M. S.; Martins, R. M.; Pinto, A. C.; Vargas, M. D. Bioorg. Med. Chem. 2005, 13, 6464. [CrossRef]

${ }^{19}$ Teixeira, M. J.; Almeida, Y. M.; Viana, J. R.; Holanda Filha, J. G.; Rodrigues, T. P.; Prata, J. R. C. Jr.; Coelho, I. C. B.; Rao, V. S. Pompeu, M. M. L. Phytother. Res. 2001, 15, 44. [CrossRef] [PubMed]

${ }^{20}$ Almeida, E. R.; Silva-Filho, A. A. A.; Santos, E. R.; Lopes, C. A. J. Ethnopharmacol. 1990, 29, 239. [CrossRef] [PubMed]

${ }^{21}$ Garnier, S.; Wolfender, J. L.; Nianga, M.; StoeckliEvans, H.; Hostettmann, K. Phytochemistry 1996, 42, 1315. [CrossRef] [PubMed]

22 Pinto, C. N.; Dantas, A. P.; De Moura, K. C. G.; Emery, F. S.; Polequevitch, P. F.; Pinto, M. C. F. R.; De Castro, S. L.; Pinto, A. V. Arzneim. Forsch./Drug Res. 2000, 50, 1120. [PubMed]

${ }^{23}$ De Moura, K. C. G.; Emery, F. S.; Neves-Pinto, C.; Pinto, M. C. F. R.; Dantas, A. P.; Salomão, K.; De Castro, S. L.; Pinto, A. V. J. Braz. Chem. Soc. 2001, 12, 325. [CrossRef]

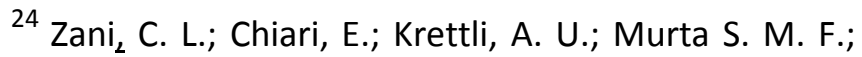
Cunningham, M. L.; Fairlamb, A. H.; Romanha, A. J. Bioorg. Med. Chem. 1997, 5, 2185. [CrossRef]
${ }^{25}$ Stagliano, K. W.; Emadi, A.; Lu, Z.; Malinakova, H. C.; Twenter, B.; Yu, M. ; Holland, L. E.; Rom, A. M.; Harwood, J. S.; Amin, R.; Johnson, A.; Yves, P. Bioorg. Med. Chem. 2006, 14, 5651. [CrossRef]

${ }^{26}$ Bringmann, G.; Reichert, Y.; Kane, V. V. Tetrahedron 2004, 60, 3539. [CrossRef]

${ }^{27}$ Hussain, H.; Krohn, K.; Ahmad, V. U.; Miana, G. A.; Greend, I. R. Arkivoc 2007, Part II, 145. [Link]

${ }^{28}$ Fedoryshyn, M.; Nur-E-Alam, M.; Zhu, L.; Luzhetskyy, A.; Rohr, J.; Bechthold, A. J. Biotechnol. 2007, 130, 32. [CrossRef]

${ }^{29}$ Salas, C.; Tapia, R. A.; Ciudad, K.; Armstrong, V.; Orellana, M.; Kemmerling, U.; Ferreira, J.; Maya, J. D.; Morello, A. Bioorg. Med. Chem. 2008, 16, 668. [CrossRef]

${ }^{30}$ Benites, J.; Valderrama, J. A.; Rivera. F.; Rojo, L.; Campos, N.; Pedro, M.; Nascimento, M. S. J. Bioorg. Med. Chem. 2008, 16, 862. [CrossRef]

${ }^{31}$ Monks, T. J.; Hanzlik, R. P.; Cohen, G. M.; Ross, D.; Graham, D. G. Toxicol. Appl. Pharmacol. 1992, 112, 2. [CrossRef] [PubMed]

${ }^{32}$ Sítio da Organização Mundial de Saúde. Disponível em: http://www.who.int/topics/chagas disease/en/>. Acesso em: 31 julho 2010.

${ }^{33}$ Castro, J. A.; De Mecca, M. M.; Bartel, L. C. Hum. Exp. Toxicol. 2006, 25, 471. [CrossRef]

${ }^{34}$ Villamil, S. F.; Stoppani, A. O. M.; Dubin, M. Method. Enzymol. 2004, 378, 67. [CrossRef]

${ }^{35}$ Rover Júnior, L.; Höehr, N. F.; Vellasco, E. A. P.; Kubota, L. T. Quim. Nova 2001, 24, 112. [CrossRef]

${ }^{36}$ Muniz, M. Ciência Hoje 1995, 115, 70. [Link]

${ }^{37}$ Fridovich, I. J. Exp. Biol. 1998, 201, 1203. [Link][PubMed]

${ }^{38}$ Adaptação de: Santos, E. V. M.; Carneiro, J. W. M.; Ferreira,V. F. Bioorg. Med. Chem. 2004, 12, 87. [CrossRef]

${ }^{39}$ Silva, M. N.; De Souza, M. C. B. V.; Ferreira, V. F.; Pinto, A. V.; Goulart, M. C. R. F.; Wardell, S. M. V.; Wardell, J. L. Arkivoc 2003, Part X, 156. [Link]

${ }^{40}$ Makin, G.; Dive, C. Trends Cell Biol. 2001, 11, S-22. [CrossRef]

${ }^{41}$ Pardee, A. B.; Li, Y. Z.; Li, C. J. Curr. Cancer Drug Targets 2002, 2, 227. [CrossRef]

42 De Moura, K. C. G.; Salomão, K. B.; Menna-Barreto R. F. S.; Emery, F. S.; Pinto M. C. F. R.; Pinto, A. V.; De Castro S. L. Eur. J. Med. Chem. 2004, 39, 639. 


\section{[CrossRef]}

${ }^{43}$ Papageorgiou, V. P.; Assimopolou, A. N.; Couladours, E. A.; Hepworth, D.; Nicolaou, K. C. Angew. Chem. Int. Ed. 1999, 38, 270. [CrossRef]

${ }^{44}$ Ferreira, V. F., ß-Lapachona. Disponível em: $<$ www.portaldosfarmacos.ccs.ufri.br/resenhas lapach ona.html>. Acesso em: 13 setembro de 2010.

${ }^{45}$ Bey, E. A.; Bentle, M. S.; Reinicke, K. E.; Dong, Y. C.; Yang, R.; Girard, L.; Minna, J. D.; Bornmann, W. G.; Gao, J.; Boothman, D. A. P. Natl. Acad. Sci. USA 2007, 104, 11832. [CrossRef]

${ }^{46}$ Reinicke, K. E.; Bey, E. A.; Bentle, M. S.; Pink, J. J.; Ingalls, S. T.; Hoppel, C. L.; Misico, R. I.; Arzac, G. M.; Burton, G.; Bornmann, W. G.; Sutton, D.; Gao, J.; Boothman, D. A. Clin. Cancer Res 2005, 11, 3055. [CrossRef] [PubMed]

${ }^{47}$ Yang, R. Y.; Kizer, D.; Wu, H.; Volckova, E.; Miao, X. S.; Ali, S. M.; Tandon, M.; Savage, R. A.; Chan, T. C. K.; Ashwell, M. A. Bioorg. Med. Chem. 2008, 16, 5635. [CrossRef]

${ }^{48}$ Hooker, S. C. J. Chem. Soc. 1892, 61, 611. [CrossRef]

${ }^{49}$ Sun, J. S.; Geiser, A. H.; Frydman, A. H. Tetrahedron Lett. 1998, 39, 8221. [CrossRef]

${ }^{50}$ Fieser, L. F. J. Am. Chem. Soc. 1927, 49, 857. [CrossRef]

${ }^{51}$ Hooker, S. C. J. Am. Chem. Soc. 1936, 58, 1181. [CrossRef]

52 Lee, Y. R.; Lee, W. K. Synth. Commun. 2004, 34, 4537. [CrossRef]

${ }^{53}$ Brandão, M. A. F.; Oliveira, A. B.; Snieckus, V. Tetrahedron Lett. 1993, 34, 2437. [CrossRef]

54 Alves, G. B. C.; Lopes, R. S. C.; Lopes, C. C.; Snieckus, V. Synthesis 1999, 11, 1875. [CrossRef]

${ }^{55}$ Ferreira, S. B.; Kaiser, C. R.; Ferreira, V. F. Org. Prep. Proced. Int. 2009, 3, 211. [CrossRef]

${ }^{56}$ Pinto, A. V.; Pinto, M. C. R. F.; Gilbert, B.; Pellegrino, J.; Mello, R. T. Trans. Royal Soc. Trop. Med. Hyg. 1977, 71, 133. [CrossRef] [PubMed]

57 Jorqueira, A.; Gouvea, R. M.; Ferreira, V. F.; Da Silva, M. N.; De Souza, M. C.; Zuma, A. A.; Cavalcanti, D. F.; Araujo, H. P.; Santos, D. O.; Bourguignon, S. C. Parasitol. Res. 2006, 99, 429. [CrossRef] [PubMed]

${ }^{58}$ Ferreira, V. F.; Jorqueira, A.; Souza, A. M. T.; Da Silva, M. N.; De Souza, M. C. B. V.; Gouvêa, R. M.; Rodrigues, C. R.; Pinto, A. V.; Castro, H. C.; Santos, D. O.; Araújo, H. P.; Bourguignon, S. C. Bioorg. Med. Chem. 2006, 14, 5459. [CrossRef]
${ }^{59}$ Bourguignon, S. C.; Castro, H.C.; Santos, D. O.; Alves, C. R.; Ferreira, V. F.; Gama, I. L.; Silva, F. C.; Seguis, W. S.; Pinho, R. T. Experimental Parasitol. 2009, 122, 91. [CrossRef] [PubMed]

${ }^{60}$ Di Chenna, P. H.; Doctorovich, V. B.; Baggio, R. F.; Garland, M. T.; Burton, G. J. Med. Chem. 2001, 44, 2486. [CrossRef] [PubMed]

${ }^{61}$ Carvalho, C. E. M.; Ferreira, V. F.; Pinto, A. V.; Pinto, M. C. F. R.; Harrison; W. Dyes Pigments 2002, 52, 209. [CrossRef]

${ }^{62}$ Renou, S. G.; Asis, S. E.; Abasolo, M. I.; Bekerman D. G.; Bruno A. M. Pharmazie 2003, 58, 690. [PubMed]

${ }^{63}$ Emery, F. S.; Moura, K. C. G; Pinto, A. V.; Pinto, M. C. F. R.; Pereira, L. B. A.; Marques, R. A.; Resumo da 24a Reunião Anual da Sociedade Brasileira de Química, Poços de Caldas, Brasil, 2001.

${ }^{64}$ Nicolaides, D. N.; Gautam, D. R.; Litinas, K. E.; Hadjipavlou-Litina, D. J.; Kontogiorgis, C. A. J. Heterocycl. Chem. 2004, 41, 605. [CrossRef]

${ }^{65}$ Ferreira, V. F.; De Souza, M. C. B. V.; Da Silva, M. N.; Pinto, A. V.; Pedido de Privilégio de Patente, INPI- PI 0200273-6, depósito em 31/01/2002.

${ }^{66}$ Ferreira, V. F.; Jorqueira, A.; Leal, K. Z.; Pimentel, H. R. X.; Seidl, P. R; Da Silva, M. N.; De Souza, M. C. B. V.; Pinto, A. V.; Wardell, J. L; Wardell, S. M. S. V. Magn. Reson. Chem. 2006, 44, 481. [CrossRef]

${ }^{67}$ Ferreira, V.F. Curr. Org. Chem. 2007, 11, 177. [Link] ${ }^{68}$ Da Silva. M. N.; Ferreira. S. B.; Jorqueira, A.; De Souza, M. C. B. V.; Pinto, A. V.; Kaiser, C. R.; Ferreira, V. F. Tetrahedron Lett. 2007, 48, 6171. [CrossRef]

${ }^{69}$ Chaves, J. P.; Pinto, M. C. F. R.; Pinto, A. V. J. Braz. Chem. Soc. 1980, 1, 22. [Link]

${ }^{70}$ Pinto, A. V.; Pinto, C. N.; Pinto, C. F. R.; Rita, R. S.; Pezzella, C. A. C.; Castro, S. L. Arzneim Forsch/Drug Res. 1997, 47, 74. [PubMed]

${ }^{71}$ Emery, F. S.; Silva; R. S. F.; De Moura, K. C. G.; Pinto, M. C. F. R.; Amorim, M. B.; Malta, V. R. S.; Santos, R. H. A. K.; Honório, M.; Da Silva, A. B. F.; Pinto, A. V. An. Acad. Bras. Ciênc. 2007, 79, 29. [CrossRef]

${ }^{72}$ Menna-Barreto, R. F. S.; Henriques-Pons, A.; Pinto, A. V.; Morgado-Diaz, J. A.; Soares, M. J.; de Castro, S. L. J. Antimicrob. Chemother. 2005, 56, 1034. [CrossRef]

${ }^{73}$ Da Silva, A. R.; Da Silva, A. M.; Ferreira, A. B.; Bernardes, B. O.; Da Costa, R. L. J. Braz. Chem. Soc. 2008, 19, 1230. [CrossRef]

${ }^{74}$ Nicolaides, D. N.; Gautam, D. R.; Litinas, K. E.; Rev. Virtual Quim. |Vol 2| |No. 2| |140-160| 
Hadjipavlou-Litina, D. J.; Fylaktakidou, K. C. Eur. J. Med. Chem. 2004, 39, 323. [CrossRef]

${ }^{75}$ Neder, K.; Marton, L. J.; Liu, L. F.; Frydman, N. Cel. Mol. Biol. 1998, 44, 465. [CrossRef]

${ }^{76}$ Oliveira-Brett, A. M.; Goulart, M. O. F.; Abreu, F. C. Bioelectrochem. 2002, 56, 53. [CrossRef]

77 Laursen, J.; Nilsen, J. Chem. Rev. 2004, 104, 1663. [CrossRef]

${ }^{78}$ Kerr, J. R. J. Infection 2000, 40, 121. [CrossRef]

${ }^{79}$ Reddy, V. M.; O'Sullivan, J. F.; Gangadharam, P. R. J. Antimicrob. Chemother. 1999, 43, 615. [CrossRef]

${ }^{80}$ Turner, J. M.; Messenger, A. J. Adv. Microb. Physiol. 1986, 27, 211. [CrossRef]

81 Jayatilake, G. S.; Thornton, M. P.; Leonard, A. C.; Grimwade, J. E.; Baker, B. J. J. Nat. Prod. 1996, 59, 293. [CrossRef]

${ }^{82}$ Neves-Pinto, C.; Malta, V. R. S.; Pinto, M. C. F. R.; Santos, R. H. A.; De Castro, S. L.; Pinto, A. V. J. Med. Chem. 2002, 45, 2112. [CrossRef]

${ }^{83}$ Silva, R. S. F.; De Amorim, M. B.; Pinto, M. C. F. R.; Emery, F. S.; Goulart, M. O. F.; Pinto, A. V. J. Braz. Chem. Soc. 2007, 18, 759. [CrossRef]

${ }^{84}$ De Andrade-Neto, V. F.; Goulart, M. O. F.; Da Silva Filho, J. F.; Da Silva, M. J.; Pinto, M. C. F. R.; Pinto, A.V.; Zalis, M. G.; Carvalho, L. H.; Krettli, A. U. Bioorg. Med. Chem. Lett. 2004, 14, 1145. [CrossRef]

${ }^{85}$ Singh, P.; Dandia, A.; Natani, K.; Sharma, V.; Ratnani, R.; Bingham, A. L.; Hursthouse, M. B.; Light, M. E. Synth. Commun. 2007, 37, 113. [CrossRef]

${ }^{86}$ Pérez-Sacau, E.; Estévez-Braum, A.; Ravelo, A. G.; Yapu, D. G.; Turba, A. G. Helv. Chim. Acta 2005, 2, 264. [CrossRef]

${ }^{87}$ Pérez-Sacau, E.; Díaz-Peñate, R. G.; Estévez-Braun, A.; Ravelo, A. G.; García-Castellano, J. M.; Pardo, L.; Campillo, M. J. Med. Chem. 2007, 50, 696. [CrossRef]

${ }^{88}$ Carvalho, C. E. M.; Brinn, I. M.; Pinto, A. V.; Pinto, M. C. F. R. J. Photochem. Photobiol. A: Chem. 1999, 123, 61. [CrossRef]

${ }^{89}$ Carvalho, C. E. M.; Brinn, I. M.; Pinto, A. V.; Pinto, M. C. F. R. J. Photochem. Photobiol. A: Chem. 2000, 136, 25. [CrossRef]

${ }^{90}$ Carvalho, C. E. M.; De Lucas, N. C.; Herrera, J. O. M.; Pinto, A. V.; Pinto, M. C. F. R.; Brinn, I. M. J. Photochem. Photobiol. A: Chem. 2004, 167, 1. [CrossRef]

91 Pinto, A. V.; Neves-Pinto, C.; Pinto, M. C. F. R.;

Rev. Virtual Quim. |Vol 2| |No. 2| |140-160|
Emery, F. S.; De Moura, K. C. G. Heterocycles 1997, 45, 2431. [CrossRef]

92 Pinto, A. V.; Carvalho, C. E. M.; De Moura, K. C. G.; Brinn, I.; Pinto, M. C. F. R. J. Chem. Res. S 1999, 650. [CrossRef]

${ }^{93}$ da Silva, F. C.; Jorqueira, A.; Gouvêa, R. M.; De Souza, M. C. B. V.; Howie, R. A.; Wardell, J. L.; Wardell, S. M. S. V; Ferreira, V. F. Synlett 2007, 3123. [CrossRef] 